\title{
Heme: From quantum spin crossover to oxygen manager of life
}

\section{Kepp, Kasper Planeta}

\section{Published in:}

Coordination Chemistry Reviews

Link to article, DOI:

10.1016/j.ccr.2016.08.008

Publication date:

2016

Document Version

Peer reviewed version

Link back to DTU Orbit

Citation (APA):

Kepp, K. P. (2016). Heme: From quantum spin crossover to oxygen manager of life. Coordination Chemistry Reviews, 344, 363-374. https://doi.org/10.1016/j.ccr.2016.08.008

\section{General rights}

Copyright and moral rights for the publications made accessible in the public portal are retained by the authors and/or other copyright owners and it is a condition of accessing publications that users recognise and abide by the legal requirements associated with these rights.

- Users may download and print one copy of any publication from the public portal for the purpose of private study or research.

- You may not further distribute the material or use it for any profit-making activity or commercial gain

- You may freely distribute the URL identifying the publication in the public portal

If you believe that this document breaches copyright please contact us providing details, and we will remove access to the work immediately and investigate your claim. 


\title{
Heme: From quantum spin crossover to oxygen manager of life
}

\section{Kasper Planeta Kepp}

Technical University of Denmark, DTU Chemistry, DK-2800 Kongens Lyngby, Denmark

*Correspondence: Email: kpj@kemi.dtu.dk

\begin{abstract}
The review discusses how the electronic structure of heme explains its central importance to oxygenbased life on Earth. Emphasis is on the chemical bonding of heme, its spin crossover, reversible $\mathrm{O}_{2}$ binding, and $\mathrm{O}-\mathrm{O}$ bond activation, put in relation to its physiological functions. The review discusses the spectroscopic and computational data that have helped to elucidate the nature of this remarkable molecular system, how it works, and how it is tuned by a range of molecular strategies. This tuning enables heme to carry out the two essential functions required for oxygen management of life, i.e. reversible oxygen binding for transport and storage, and oxygen activation for use in catalytic processes.
\end{abstract}

Key words: Heme, oxygen binding, iron-oxygen bond, back-bonding, electronic structure, DFT 


\section{Table of Contents:}

1. Introduction

2. The case for iron

3. The case for porphyrin

4. $\mathrm{HemeO}_{2}$ : Pauling, Weiss, McClure, and Goddard

5. $\mathrm{HemeO}_{2}$ : Towards the current consensus

6. Modulation of the electronic structure and function of heme

7. Dual function of heme proteins by evolved differences in protein polarization

8. Ligand binding to heme: Forbidden but feasible

9. Binding of $\mathrm{CO}$ and $\mathrm{NO}$ to heme

10. Conclusions 


\section{Introduction}

It is remarkable that the primary biological oxidant on this planet, $\mathrm{O}_{2}$, has a triplet ${ }^{3} \Sigma_{\mathrm{g}}{ }^{-}$ground state with two unpaired, parallel-spin electrons due to the quantum mechanical auf-bau principle and Hund's Rule applied to its 16 electrons[1][2].

Among relevant electron acceptors, oxygen is unique as the atom that, when attached to carbon, produces the largest variety of simple, yet diverse organic functional groups. Oxygen is plentiful in water, the medium of life that was abundant in the early, reducing atmosphere of Earth. Before the use of water as electron donor and oxygen as electron acceptor, hydrogen and sulfur were used in photosynthetic early life forms [3]. Thus, previously, $\mathrm{O}_{2}$ was present in much smaller and originally only trace amounts [4][5]. However, in the wake of the evolution of oxygenic photosynthesis at least 2 billion years ago in ancestors of current-day cyanobacteria [6], $\mathrm{O}_{2}$ is now conveniently available at roughly one fifth of our atmosphere's composition, a very visible symptom of the beautiful harmony between the planet's primary producers and heterotrophic biomass oxidizers. The transition of $\mathrm{O}_{2}$ from a status as inconvenient pollutant or at best, sporadic signaling molecule, to a central role in the major cycles of energy and mass is one of the most important events in the history of Earth [7][8][9].

Even at the earliest times, organisms had to cope with $\mathrm{O}_{2}$, if nothing else then to prevent its rare but dangerous conversion into toxic radicals [8][10]. The evolution of oxygen-managing systems is therefore substantially older than the age where $\mathrm{O}_{2}$ rose to prominence [8]. This oxygen management system was based on proteins that, sometimes in connection with small anti-oxidant molecules, used transition metal ions with unpaired d-electrons to quench the unpaired electrons of oxygen-based substrates. Among such systems, the iron-porphyrin cofactor heme is the protagonist [11].

While heme and its various proteins have been the subject of massive scrutiny, this particular review will aim at a hopefully new perspective on heme's coordination chemistry and chemical bonding 
in direct relation to its evolved function as oxygen manager. It may be a comfort to some that indeed heme's role in oxygen management is by no means arbitrary [11][12]. To those who already appreciate this, the review will hopefully strengthen the appreciation that heme, rather than being just a convenient or smart choice, is a superbly fine-tuned molecule in all aspects of its electronic structure, chemical bonding, and associated biological functions.

The review covers only those specific points that relate directly to electronic structure and chemical bonding of heme and its immediate adducts with small ligands, with sad but required (for the purpose of focus) neglect of all the interesting chemistry occurring beyond ligand binding: Many exquisite reviews deal with such wider aspects of heme chemistry and biochemistry, including the general structure and function of the heme proteins [13][14], their stability, oxygen transport and storage [15][16], their electron transfer reactions [17][18], the cytochrome $c$ oxidase based respiration [19][20], the accomplishments in the field of synthetic heme models [21][22][23][24], catalytic functions of heme oxygenases [25][26], heme peroxidases [27], and heme catalases [28][29], cytochrome $\mathrm{P}_{450}$ degradation of drugs and other xeno-molecules [30][31], the degradation of the cofactor by heme oxygenase [32], and various spectroscopic [29][33] and biological aspects of heme [34][35], including its molecular evolution [12][36][37][38].

\section{The case for iron}

The element having 26 protons is notable for its abundance: As the main end product of exothermic nucleosynthesis of larger stars [39][40], this element makes up most of our planet's core and is Earth's most abundant element by mass and the fourth-most common element of the crust [41]. 
Beyond its abundance, iron is also notable for being in the middle of the first row of the d-block, together with manganese. This provides a moderate effective nuclear charge, borderline Lewis acid properties [42], and a not too oxophilic, not too thiophilic metal ion that routinely forms complexes with both oxygen-, sulfur- [43][44], and nitrogen-donor ligands [45][46]; all three types of ligands to iron are encountered in some hemes, a notable example being cytochromes P450 [47]. Once associated with other atoms, the richness and modest energy separations of the various electronic configurations of the dorbitals produce important degrees of freedom and spin-crossover properties [48].

When iron(III) binds in a weak ligand field of $\mathrm{O}_{\mathrm{h}}$ symmetry, it produces a highly paramagnetic ${ }^{6} \mathrm{~A}_{1}$ state having a half-filled $\mathrm{d}$-shell with only spin-forbidden $\mathrm{d}-\mathrm{d}$ transitions. However, in a stronger ligand field, the weakly Jahn-Teller distorted low-spin state offers rich transitions, as does the iron(II) complexes in both weak and strong ligand fields: Such ligand-field transitions of iron in porphyrin were familiar to our ancestors as the characteristic red color of blood that largely defines the human psychological and cultural connotations of the color representing courage, war, danger, and suffering. Incidentally, $\pi-\pi^{*}$ transitions within the porphyrin-derived chlorophylls are also responsible for the green color of plants, associated with nature, life and hope, so the reader may perhaps agree that porphyrin has had vast (but alas! rarely appreciated) cultural consequences.

Low-spin iron(II) with six d-electrons is notable for its maximal ligand field stabilization energy of $12 / 5 \Delta_{\mathrm{o}}$ in octahedral symmetry. Such complexes are relatively inert in terms of ligand substitution reactions, and the fully occupied set of $\mathrm{d}_{\pi}$ orbitals enable strong back-bonding, a feature that is vital for the binding and activation of $\mathrm{O}_{2}$ to be discussed in the following.

Iron is also notable for its many potentially available oxidation states, another consequence of its position in the middle of the d-block. However, on the surface of Earth, the oxidation states (II) and (III) 
are most relevant and conveniently close as measured by the standard half reduction potential of iron(III) of $0.77 \mathrm{~V}$ under acidic conditions, which becomes even smaller at typical biological conditions [49].

The iron(II)-iron(III) redox couple can produce fast electron transfer in both high-spin and lowspin octahedral ligand fields, as the sixth redox-active electron shuffles between low-lying $\mathrm{t}_{2 \mathrm{~g}}$-orbitals that point away from the metal-ligand bonds: this minimizes the change in metal-ligand bond lengths upon electron transfer and reduces reorganization energies. This advantage of the $\mathrm{d}^{5} / \mathrm{d}^{6}$ redox pair is unique among biologically available transition metal redox pairs, and the logical alternatives such as $d^{3} / d^{4}$ (e.g. $\left.M n(I V / I I I)\right), d^{4} / d^{5}$ (e.g. $\left.M n(I I I / I I)\right), d^{6} / d^{7}$ (e.g. Co(III/II)), $d^{7} / d^{8}\left(\right.$ e.g. Ni(III/II)) or $d^{8} / d^{9}$ (e.g. $\mathrm{Cu}(\mathrm{II} / \mathrm{III})$ or $\mathrm{Ni}(\mathrm{II}) / \mathrm{Ni}(\mathrm{I}))$ or $\mathrm{d}^{9} / \mathrm{d}^{10}(\mathrm{Cu}(\mathrm{II}) / \mathrm{Cu}(\mathrm{I})$ all have a change in occupation of the ligand-directed d-orbitals in either high-spin or low-spin. Redox couples of $\mathrm{d}^{2} / \mathrm{d}^{3}$ and below based on $\mathrm{Ti}$ and $\mathrm{Cr}$ would not suffer such problems but would instead be highly oxophilic and thus not equally suitable. Incidentally, this design principle also defines the $\mathrm{T}_{\mathrm{d}}$-symmetric iron-sulfur clusters, which are high-spin and thus transfer electrons in the low-lying degenerate $e$ level [50][51]. These circumstances are arguably a major reason why iron(II/III) is nature's predominant redox couple.

\section{The case for porphyrin}

The question why porphyrin evolved to handle oxygen dates back to the time before oxygen was the major electron acceptor, to the very origin of life [36], but also relates to photosynthesis based on chlorophyll, which, like heme, uses porphyrin [12] and to the corrins that emerged from the same

uroporphyrinogen III precursor perhaps as early as DNA[36]; corrin's Co-C bond-cleavage-coupled carbon rearrangements are involved in the synthesis of DNA parts [52]. Heme is a relatively later stage in the synthesis of tetrapyrrole cofactors and most likely evolved two billion years ago [53], still long 
before the emergence of animals: Ancient heme proteins having the globin fold structure worked as gas sensors in archaea and bacteria [54][55].

Several advantages of the porphyrin ligand as the basis of life processes are evident as compiled in the following and summarized in Figure 1:

(i) First, the high $\mathrm{D}_{4 \mathrm{~h}}$ symmetry the central part of porphyrin, porphine, implies a relatively simple synthetic pathway based on eight units of $\delta$-aminolevulinate [56][57]. A simple synthesis is plausibly an evolutionary advantage and a premise for early use of porphyrin, since the evolution of tetrapyrroles is thought to reflect the increasing sophistication of biosynthetic pathways leading ultimately to bacteriochlorophylls and hemes [12][58]. This hypothesis has been challenged in some aspects, as the more complex biosynthesis of bacteriochlorophyll may have evolved before that of chlorophyll [59]. Uroporphyrinogen can be made under relatively simple conditions, i.e. the precursor and common ancestor of all major tetrapyrroles may have been available before the biosynthetic routes were established [60].

(ii) As a second advantage, the symmetry that eases synthesis of the ligand also imparts it with a tetradentate coordination mode that produces high thermodynamic stability of the coordination complex formed upon binding to a central metal ion, viz. the chelate effect [61]; without the chelate-afforded stability, $\mathrm{Fe}$ (II) could be prone to be released, at least in the more labile high-spin state, and in the soluble form, it would engage in converting the less toxic hydrogen peroxide into highly reactive hydroxyl radicals, viz. the Fenton reaction, Equation (1) [62]:

$$
\mathrm{Fe}^{2+}(\mathrm{aq})+\mathrm{H}_{2} \mathrm{O}_{2} \rightarrow \mathrm{Fe}^{3+}+\mathrm{HO} \bullet+\mathrm{OH}^{-}
$$

Thus, the tetradentate coordination mode of porphyrin is advantageous to an organism that wants to minimize risk of $\mathrm{Fe}(\mathrm{II})$ leaking. 
(iii) A third advantage of porphyrins is that the equatorial ligand field of porphyrin dampens changes in metal-ligand bond lengths, which is very useful in electron transfer reactions where the local molecular geometries of the redox partners should ideally change minimally to facilitate high electron transfer rates, viz. the reorganization energy of Marcus-Hush theory [63][64][65]. The geometric changes that do take place are distributed over a large area, due to the delocalized $\pi$-system of the ligand, so that reorganization energies become very small for iron porphyrin systems [66][67].

\section{Fully conjugated $\pi$-system:}

$\pi-\pi^{*}$ transitions \& aromatic stability rigid structure gives low reorganization energy

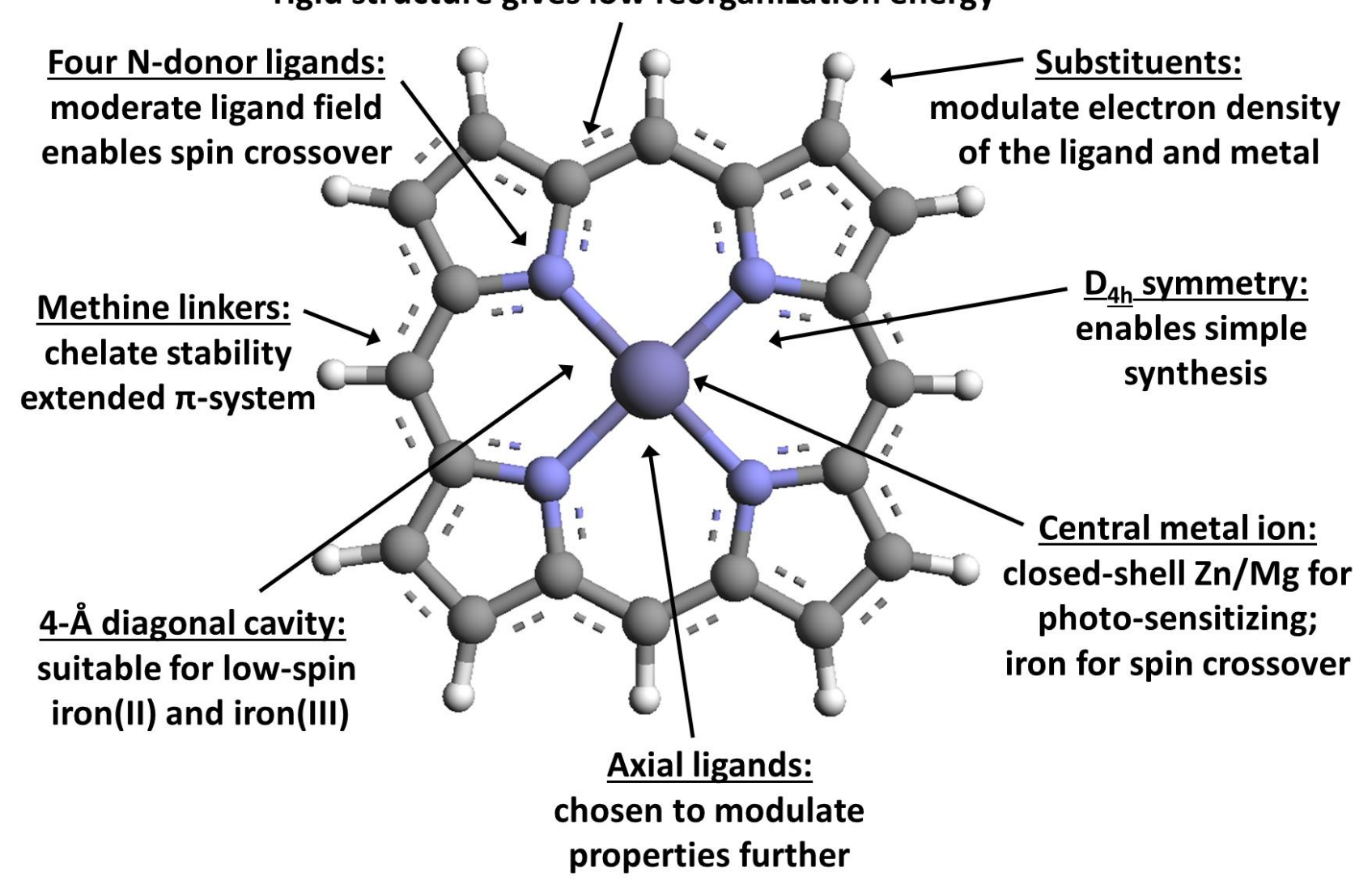

Figure 1. The case for porphyrin. The combination of properties that this ligand offers makes it uniquely suited for life's most important processes, photosynthesis and $\mathrm{O}_{2}$-management. 
(iv) Fourth, the complete $\pi$-system of porphyrin produces 26 perfectly delocalized $\pi$-electrons that fulfil Hückel's $4 n+2$ rule of aromaticity [68] and produce a characteristic energy gap between $\pi$ and $\pi^{*}$ orbitals. The corresponding violet transition at $\sim 400 \mathrm{~nm}(\sim 3 \mathrm{eV})$ is known as the Soret (or B) band [69]. This transition, upon proper modification as achieved in the chlorophylls, is ideal for harvesting photon energy of a magnitude suitable for life: To appreciate this, for a particle in a 1-dimensional box to have the first excited state at $\sim 1 \mathrm{eV}$ it must possess a size of $\sim 1 \mathrm{~nm}$, approximately the size of porphyrin. Thus, the confined nano-size $\pi$-system of porphyrin makes the cofactor a 2 -dimensional quantum dot, whose excitation properties can be tuned by the substituents on the rings. In addition, porphyrin has a second band, called the Q-band. The Soret and Q-bands can be approximated by the Gouterman model of the four frontier $\pi$-orbitals (two occupied and two unoccupied) [70][71]. As exquisite photosensitizers of life, modified porphyrins are now widely investigated for the potential use as sensitizer units in man-made solar cells [72][73][74].

The fact that life is largely based on the so-called "visible" part of the electromagnetic spectrum is trivial considering that this part borders the UV region of photon energies that spontaneously cleave single covalent bonds. A typical carbon-carbon single bond dissociation energy is $\sim 4 \mathrm{eV}$, and this constitutes a fundamental limit for the highest energy that can be harvested without suffering the arbitrary photolytic cleavage of typical organic molecules of life. It is notable that porphyrin has its much-studied absorption bands at $\sim 400 \mathrm{~nm}$ and $\sim 670 \mathrm{~nm}$, intriguingly within $\sim 0.1 \mathrm{eV}$ of the boundary of the visible spectrum of humans.

(v) A fifth advantage of porphyrin is the fact that the central cavity has a diagonal $\mathrm{N}-\mathrm{N}$ distance of approximately $4 \AA$ (corresponding to closest N-N distances of $\sim 2.83 \AA$, using Pythagoras' equation). This produces a cavity with a size ideally suited for binding different metal ions with high affinity. For 
the purpose of light harvesting, such metal ions should be closed-shell zinc or magnesium not to quench the photo-excitations [75], but with other transition metal ions such as iron(II), which is incorporated into protoporhyrin IX in a late step of the heme synthesis [11], the unoccupied d-orbitals quench the excitations but instead enable spin-forbidden oxidative chemistry while maintaining the other advantages of the ligand system. This profound dichotomy makes porphyrin a cornerstone of both photosynthesis and oxidative respiration.

(vi) Sixth, the $\mathrm{sp}^{2}$-hybridized N-donor atoms produce a moderate ligand-field with almost equal propensity towards high- and low-spin. This can be seen from the spectrochemical series [76][77], or, since this series reflects the absorption band of a series of complexes with variable ligands rather than the thermodynamic spin state preference [78], from the recently proposed thermochemical spin propensity that takes into account orbital pairing, zero-point energy, and entropy contributions [79]: The typical N-donor ligands produce the smallest gaps between high- and low-spin. The particular moderate ligand-field strength of the $\mathrm{N}$-donor ligands renders iron porphyrins effective spin crossover (SCO) systems [80][81]. The combination of iron and nitrogen is so optimal that the vast majority of SCO systems produced in the laboratory by humans are iron complexes with $\mathrm{N}$-donor ligands [48][82].

(vii) A seventh notable advantage of porphyrin and related tetrapyrroles is the tunable size of the central cavity, which is a remarkable case of molecular co-evolution of ligand and metal ion: Porphyrin's cavity is substantially larger than corrin's cavity, which was evolved for low-spin cobalt chemistry [83]. Porphyrin fits well the iron(II) and iron(III) low-spin ionic radii but is somewhat too large for cobalt. A $\sim 0.2 \AA$ reduction in cavity size is characteristic of corrins; this makes a better fit to low-spin cobalt, which, due to its increased effective nuclear charge, is smaller than iron for a given oxidation state [66]. The fit between ionic radii and cavity contributes to the thermodynamic preference for cobalt with corrin 
and iron with porphyrin vs. the opposite alternatives [66] seen from isodesmic substitution reactions studied with DFT:

$$
\text { CoPorXY + FeCorXY } \rightarrow \text { FePorXY + CoCorXY }
$$

Por $=$ porphyrin, Cor $=$ corrin, and $\mathrm{X}$ and $\mathrm{Y}$ represent a variety of axial ligands (including none) [66][84]. Such substitution reactions constitute one of the distinct cases where theoretical chemistry can achieve chemical accuracy because of the large cancellation of systematic errors[85]. The thermodynamic preference of native metal-ligand combinations is a symptom of molecular co-evolution, and one of the few examples where such co-evolution can be quantified. Corrin carries a charge of -1 in its deprotonated form to encompass the low-spin and low-valent organometallic cobalt chemistry [52]. In practice, this was achieved by a specific biosynthetic pathway leading from uroporphyrinogen III, the "common ancestor" of all tetrapyrroles, to the corrins, F430, and siroheme, with the other pathway continuing towards chlorophylls and the main hemes [86].

Incidentally, high-spin iron(II) does not stay within the plane of the porphyrin cavity [84][87]; this fitting issue of high-spin vs. low-spin iron is not by itself due to the increased size of high-spin states[88], but rather to minimization of the repulsion between the $e_{\mathrm{g}}$-electrons of the high-spin state and the $\mathrm{N}$-donor electrons, a repulsion that also gives rise to the longer bonds and deduced larger size of the high-spin state; these points were first emphasized by Boyd and co-workers [89][90]. The movement is thought to influence the steric-mechanical conversion from tense to relaxed states of hemoglobin upon axial $\mathrm{O}_{2}$-binding, as iron moves out of the porphyrin plane upon going high-spin in the deoxy form [91][92]. 

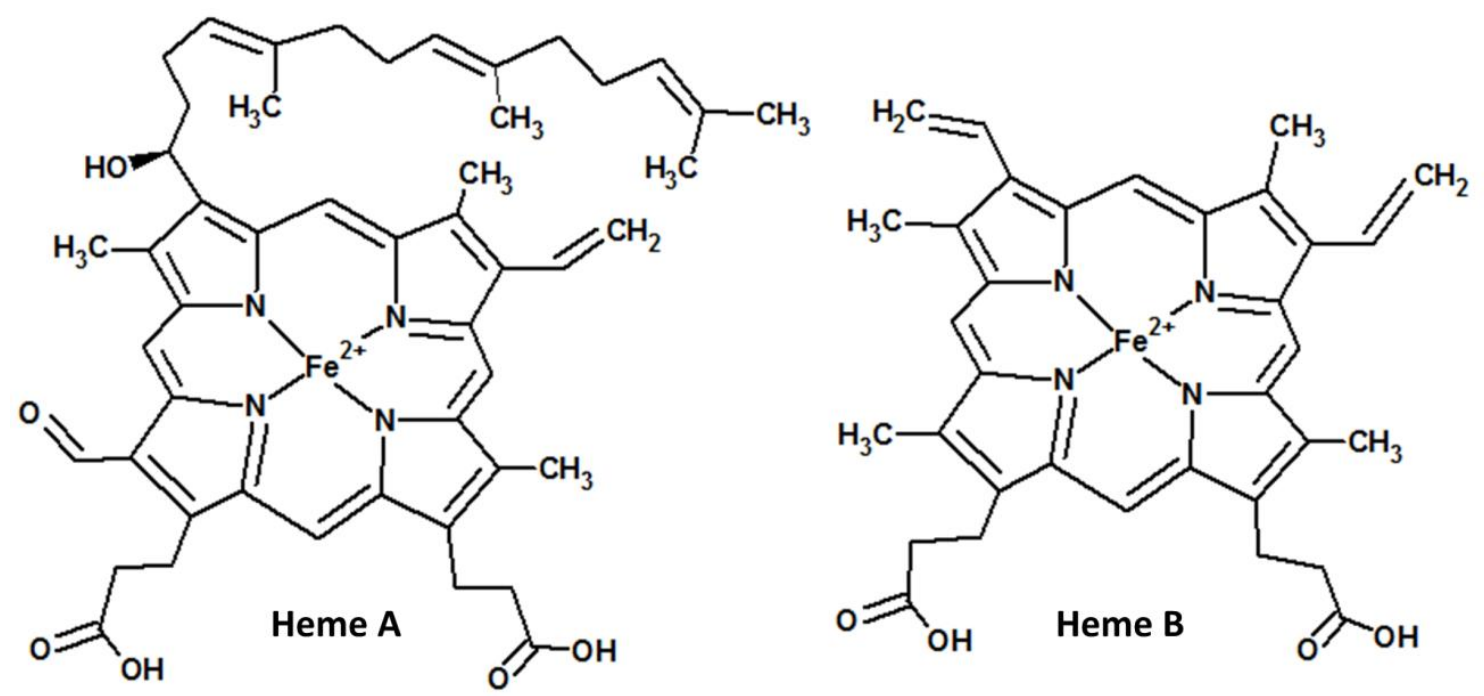

Figure 2. The two most predominant heme variants, Heme A and Heme B.

\section{HemeO2: Pauling, Weiss, McClure, and Goddard}

The heme systems contain the porphyrin ring with iron bound and different substituents that define the different types of hemes [93][94], the most notable being hemes A and B (Figure 2). The detailed electronic structure of heme has been of interest since the co-factor was found in a range of different proteins [95]. Heme's use of the porphyrin ligand, with its advantages outlined above, distinguishes it from active sites of non-heme iron proteins that use amino acids as ligands, notably by the orbital interplay between iron and porphyrin's formidable conjugated $\pi$-system, which is absent in any amino acid-based ligands [96].

Pauling and Coryell [97] first noticed that the adduct of $\mathrm{O}_{2}$ bound to ferrous heme proteins was diamagnetic, suggesting that the spins had been inverted during binding; their predicted bent geometry of the adduct was later confirmed in model compounds and proteins [23][98]. Immediately, this presented a new problem, i.e. how heme facilitates the spin-forbidden binding of ligands so vital to higher life forms on Earth. Two prerequisites were needed to elucidate the mechanism behind this process: i) an 
understanding of the heme- $\mathrm{O}_{2}$ adduct itself, and ii) an understanding of the spin-inversion process occurring during $\mathrm{O}_{2}$ binding to heme.

The first issue proved controversial: Pauling and Coryell [97] suggested two schemes, one which was essentially a neutral $\mathrm{O}=\mathrm{O}$ binding with two of its electrons to iron to produce a formally iron(II) if both the bonding electrons were confined to $\mathrm{O}_{2}$, corresponding to the non-bonding limit of neutral parts, but a formally iron(I) if the Fe-O bond were to be considered covalent. The other scheme had a single bonded $\mathrm{O}-\mathrm{O}$ bound with a double bond to iron, i.e. $\mathrm{Fe}=\mathrm{O}-\mathrm{O}$. From covalent (neutral ligand) counting, this would give iron(II) as well, but Pauling and Coryell considered the structure unlikely for "steric reasons".

In 1960, McClure suggested a valence-bond formulation based on triplet-triplet coupling, which is appealing by the low promotion energies required to access these states, rather than the singlet states [99]. In 1964, Weiss suggested, based on analogy to chemical reactions in aqueous solution, that the true ferrous hemeO ${ }_{2}$ adduct was mainly of the superoxo-iron(III) type caused by "electron transfer" from iron to $\mathrm{O}_{2}[100]$ (please note that this discussion dealt only with the formal $\mathrm{Fe}(\mathrm{II})-\mathrm{O}_{2}$ bond; the first characterization of the formal $\mathrm{Fe}(\mathrm{III})-\mathrm{O}_{2}$ bond of ferric heme was only achieved recently [101]). In his response to Weiss [102], Pauling maintained the view that the adduct is mainly ferrous in nature, arguing for the importance of maintaining oxidation states and the diamagnetic nature of the adduct.

Goddard and Olafson suggested an ozone model of the adduct in 1975 which emphasized the four-electron three-center bond with maintained triplet state of dioxygen as in the McClure model with less electronic reorganization to explain the reversible binding [103]. In 1977, Pauling maintained his original view again [104], the same year that Huynh, Case, and Karplus did a first attempt to bridge these views by performing early quantum chemical calculations that diplomatically emphasized the importance of both Weiss and Pauling resonance forms [105]. 
The disagreement rested largely on the different views obtained from simple Lewis structures, molecular orbitals, and valence bond models, and can be conveniently unified by increased valence structures as argued by Harcourt [106] in a comment to the first CASSCF study of the problem by Yamamoto and Kashiwagi [107]; Harcourt later summarized these structures [108][109]. What then really matters is to pinpoint the electronic structure that accurately reproduces the experimental observables and at the same time provides a useful model for further interpretation and prediction.

\section{5. $\mathrm{HemeO}_{2}$ : Towards the current consensus}

Various techniques have been helpful in elucidating heme's electronic structure: Vibrational spectroscopy provides insight into the strength of the bonds of the heme systems [110][111]. Magnetic techniques such as electron paramagnetic resonance (EPR) [112][113], magnetic circular dichroism [114], and Mössbauer spectroscopy [115] have been instrumental [116]. The orbitals involved during excitation of heme electrons in solution can be described from L-edge resonant inelastic X-ray scattering [117]. Many Mössbauer data were measured in the seventies: Deoxyheme has an isomer shift of $\sim 0.9$ $\pm 0.05 \mathrm{~mm} / \mathrm{s}$ [118][119]; but it is much reduced in the $\mathrm{O}_{2}$-heme adduct to $\sim 0.27 \pm 0.05 \mathrm{~mm} / \mathrm{s}$ [120], or approximately $0.35 \mathrm{~mm} / \mathrm{s}$ at $0 \mathrm{~K}$ when accounting for temperature [121]. Recently, mass spectrometry has been useful in monitoring ligand binding to heme [122].

During the 1990s, computer power and new accurate quantum chemistry methods opened the door for much more accurate computational studies of medium-sized molecular systems, including tetrapyrroles. Some of the earliest applications of DFT to porhyrins were carried out by Ghosh and coworkers [123][124], Jones, Hinman, and Ziegler [125], and Kozlowski, Zgierski, and Pulay [126], and CASPT2 [127] calculations by Roos and co-workers [128]. Oldfield's group did the first detailed theoretical study of Mössbauer parameters affecting electronic structure of heme models [129][130]. 


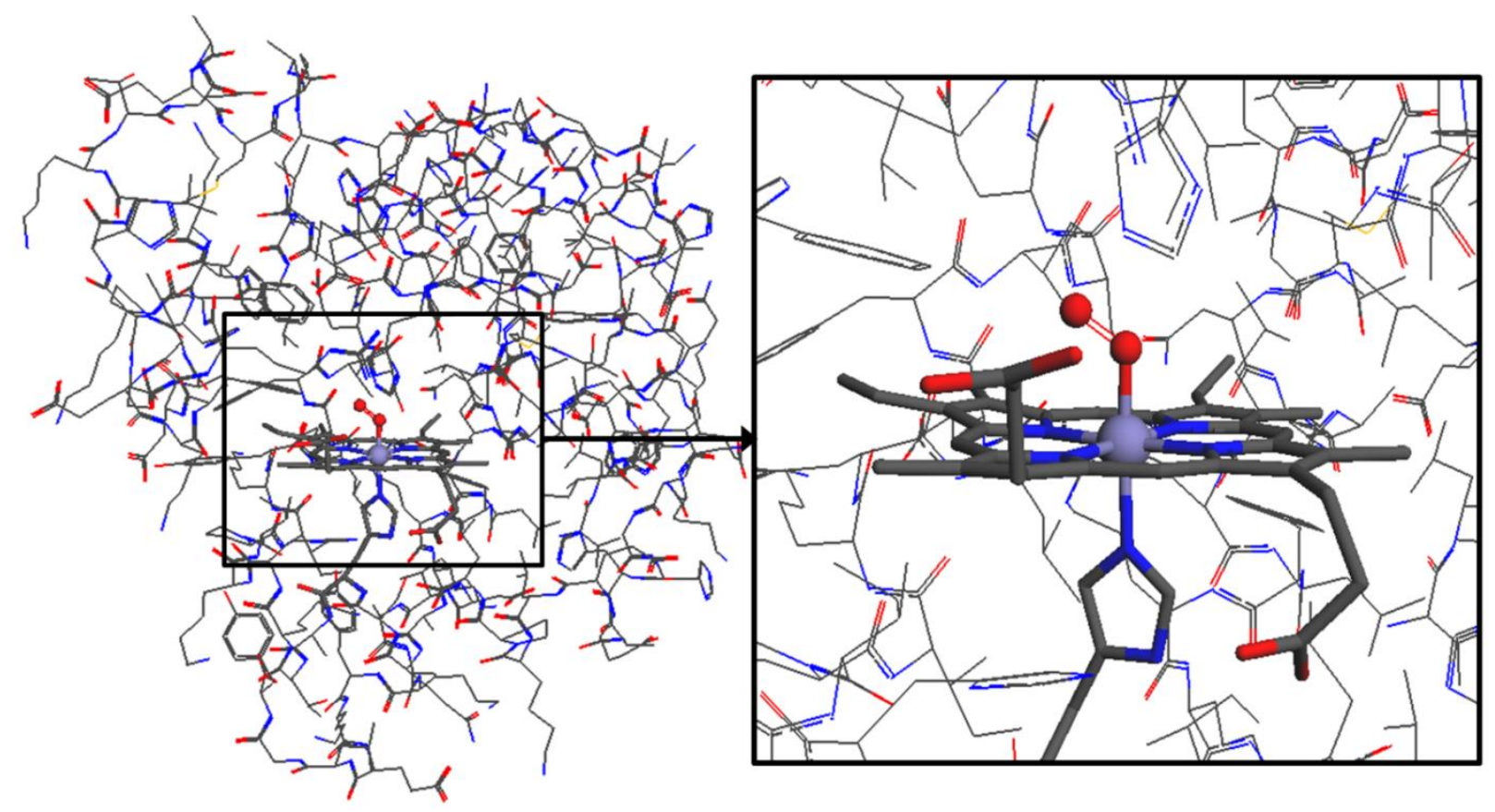

Figure 3. The atomic-resolution $(R=1.0 \AA)$ structure of sperm whale myoglobin with $\mathrm{O}_{2}$ bound to heme (PDB code 1A6M [131]). $\mathrm{O}_{2}$ binds in a bent form, with a $\mathrm{Fe}-\mathrm{O}-\mathrm{O}$ angle of $122.5^{\circ}$; the $\mathrm{Fe}-\mathrm{O}$ bond length is $1.81 \AA$, the $\mathrm{O}-\mathrm{O}$ bond length is $1.24 \AA$, and the hydrogen-bonding nitrogen of the distal histidine is $\sim 3 \AA$ away from oxygen.

Some relevant facts that have emerged are i) the $\mathrm{O}-\mathrm{O}$ bond is substantially weakened compared to free $\mathrm{O}_{2}$, its vibrational wave number of $1100 \mathrm{~cm}^{-1}$ being close to that of superoxide, as first observed by Collman's group [110]; ii) the isomer shift of iron substantially decreases from $\sim 0.9$ to $\sim 0.3 \mathrm{~mm} / \mathrm{s}$ upon binding $\mathrm{O}_{2}$ in support of partial iron oxidation [115]; iii) the bond is bent as evident now from crystal structures of many proteins and heme models, with a notable example of the $\mathrm{HemeO}_{2}$ adduct of myoglobin given in Figure 3, based on the crystal structure 1A6M [131]; iv) the adduct is EPR-silent in an apparent singlet state [97]; v) the optical excitation spectrum of oxyheme measured by Eaton et al. features, in addition to the $\pi-\pi^{*}$ bands, two d-d transitions and five transitions of the $\mathrm{FeO}_{2}$ moiety that 
provide important reference data for an interpretation of the electronic structure [132]. A first attempt to describe this spectrum quantitatively was reported by Nakatsuji et al. in 1996 [133].

In 2004, the multi-state CASPT2 method [127] by Roos and co-workers in Lund was substantially improved to provide accurate correlation energies and electronic absorption spectra of transition metal systems [134]. This enabled a multi-configurational description with account of both dynamic and nondynamic correlation of the various electronic configurations involved in the $\mathrm{Fe}-\mathrm{O}_{2}$ bond thus moving beyond the Pauling-Weiss debate based on two different single-configuration states. The problem thus seemed ideally suited for the newly improved multi-state CASPT2 method. The electronic experimental absorption spectrum and isomer shifts could be modeled accurately, thus capturing for the first time all these features in one electronic structure [135].

However, interpretation depends on model language, orbital localization, and transformation between valence bond and orbital formalisms: In terms of molecular orbital theory, the wave function was a multi-configurational state dominated by the Pauling configuration [135]; however, if one uses valence bond theory considerations, it can be interpreted as having large Weiss character [136]. Thus, the multi-configurational state produced from CASPT2 [135] is interpreted differently by different models. This partly explains why the trenches were so deeply dug during the exchange between Pauling, Goddard, McClure, and Weiss; all were right, and all were wrong.

Later, the groups of Pierloot [137][138][139], Shaik [140][141], and Ghosh [142][143] carried the study of hemes by CASPT2 much further. According to Shaik and co-workers, the Weiss form is further increased upon polarization effects by condense media and hydrogen bonding [140]. This is because such effects will increase the weight of the polar Weiss configuration, in particular if hydrogen bond to $\mathrm{O}_{2}$ enables further back-bonding, and DFT is largely consistent with the experimental and highlevel computational data [144]. In terms of valence structures, the ground state was summarized by Shaik 
and Chen as having contributions from both Weiss, Pauling, and McClure forms, the first being dominating [141].

Ironically DFT ends up providing a useful language after all [141]: The charge assignments to $\mathrm{O}_{2}$ are very dependent on calculation scheme, and both the orbitals, valence structures, and atomic charges that defined the Weiss-Pauling debate are non-observable. In contrast, the electron density is observable as are the geometries and spectroscopic data summarized above. DFT is in agreement with these experimental facts (however less accurate for the d-d transitions than multi-state CASPT2) [135]. "DFT" covers a wide range of applied functionals that tend to give different quantitative results even if the qualitative electronic structure is reasonably similar [85]. This is very much the case also for iron porphyrin systems where the gap between spin states and the $\mathrm{O}_{2}$-binding affinity are two critical properties that should be accurately modeled [80]; in fact often, a functional that is accurate for one property is not for the other of these two [145]. However, if one accounts for the systematic effects of zero-point energies and vibrational entropy, which favor high-spin and weakens $\mathrm{O}_{2}$-binding, and dispersion and relativistic effects, which favor low-spin and stronger binding, accurate results are obtained with the functional TPSSh for both spin gaps and binding enthalpies [80][121][146].

The $\mathrm{Fe}-\mathrm{O}_{2}$ bond is explained as follows: The $\mathrm{O}_{2}$ molecule approaches high-spin deoxyheme to form a low-spin state; the actual spin transition is described later in this review. The adduct is represented by two major movements of electron density, one via the $\sigma$-donation from a lone pair on $\mathrm{O}_{2}$ into the bonding region with iron, which reduces electron density formally assigned to $\mathrm{O}_{2}$, and another opposite to this via back-bonding into the orthogonal $\pi^{*}$-system of $\mathrm{O}_{2}$, which increases charge on $\mathrm{O}_{2}$. The resulting adduct has an $\mathrm{O}-\mathrm{O}$ bond that has been weakened by back-bonding to resemble superoxide, but with some charge density having been donated to iron, so that the oxyheme adduct becomes a mixture of Weiss and Pauling forms. Available experimental data are consistent with a major role of back-bonding 
[121][135][147], which is implicit in the "electron transfer" model suggested by Weiss. Finally, the spin polarization of the unrestricted singlet configuration obtained from DFT [144] represents an approximation to a real state with unpaired electron density in various parts of space, notably in the antibonding $\pi^{*}$-system of $\mathrm{O}_{2}$ and on iron, that couples to produce an EPR-silent singlet state. From a strict wave function point of view, this DFT singlet is not pure and not complete, but the density, when sculpted by an accurate functional, provides accurate observables, e.g. structures, Mössbauer isomer shifts and vibration frequencies [146], also for thermochemical energies and barriers to an extent that is not yet reported with similar accuracy for CASPT2 or any other method [121].

Back-bonding of d-electrons into the partly filled $\pi^{*}$ orbitals of the ligand is quite common when transition metal ions have available occupied $d_{\pi}$ orbitals $\left(d_{x z}, d_{y z}\right.$, if the $\mathrm{z}$-axis follows the metal-ligand bond) and the ligand has empty or partly filled $\pi^{*}$ orbitals at an energy comparable to the d-orbitals. As a $\pi$-acceptor ligand binds more tightly to the metal via its $\sigma$-donation to strengthen the metal-ligand bond, it also increases $\pi^{*}$-back-bonding to weaken the intra-ligand bond. Vibrational spectroscopy, in particular resonance-Raman spectroscopy, has been particularly useful in elucidating the nature of the $\mathrm{FeO}_{2}$ moiety with emphasis on this type of back-bonding [147].

Back-bonding is also evident from the effect of distal hydrogen bonds on heme systems [146]. If back-bonding is indeed a major factor in determining the electronic structure, hydrogen bonding to a lone pair of oxygen should work to increase back-bonding by lowering the energy of the $\pi^{*}$ and thus increase its weight in the total wave function. This is indeed seen and correlates with a consistent tendency of reducing isomer shifts and increasing $\mathrm{O}-\mathrm{O}$ bond lengths and spin densities on iron as the back-bonding character increases [146].

Recently, the group of Solomon has studied a synthetic $\mathrm{O}_{2}$-heme adduct with L-edge X-ray absorption spectroscopy, which provided a new detailed picture of the orbital interactions involved in 
the adduct; this may prove a very useful technique in the study of orbital contributions to $\mathrm{Fe}-\mathrm{O}_{2}$ bonding in various types of heme systems [148].

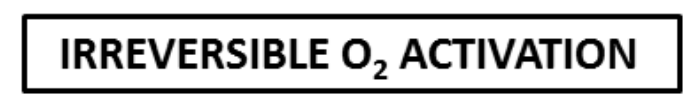

WEISS

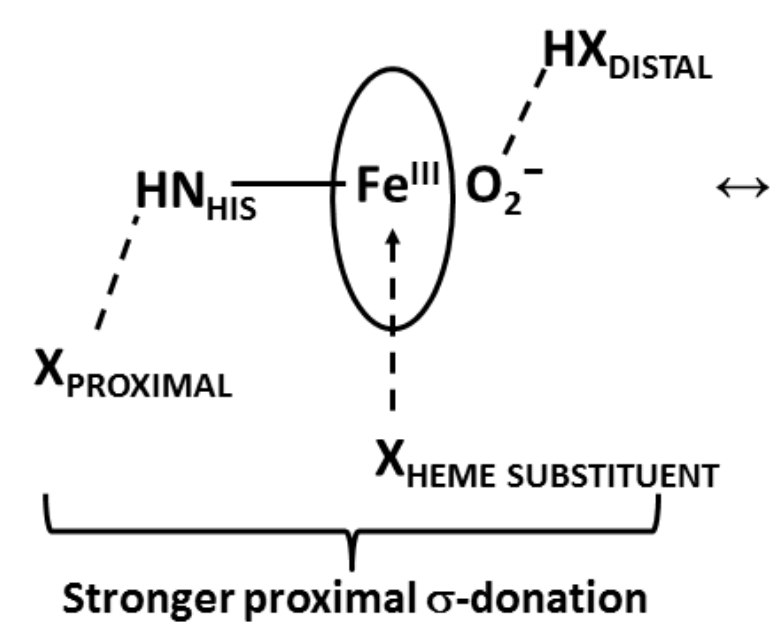

Equatorial electron donation

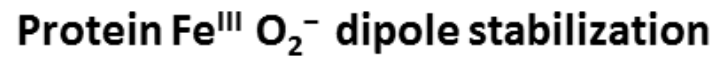
Stronger distal hydrogen bond Higher $\mathrm{O}_{2}$ affinity

Stronger back-bonding to $\mathrm{O}_{2} \pi^{*}$ Highly reduced $0-0$ strength
REVERSIBLE $\mathrm{O}_{2}$ TRANSPORT

PAULING \& MCCLURE

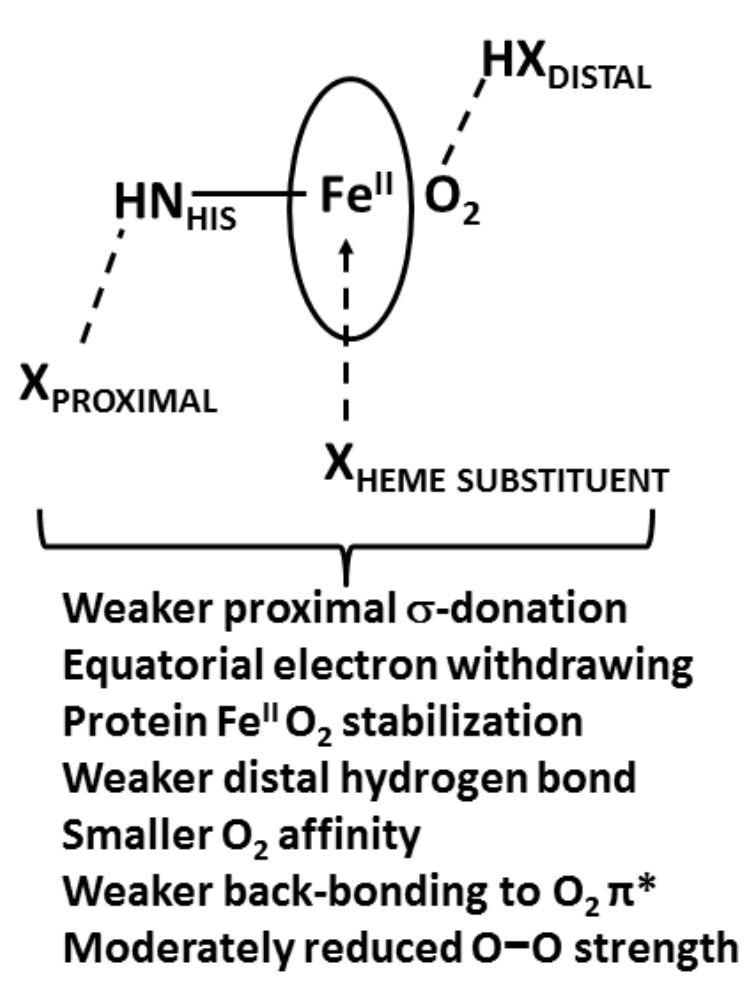

Figure 4. The modulation strategies towards either irreversible $\mathrm{O}_{2}$-activation or reversible $\mathrm{O}_{2}$ transport in heme proteins.

6. Modulation of the electronic structure and function of heme 
Considering the remarkable ability of heme proteins to engage in distinct types of chemical reactivity such as reversible $\mathrm{O}_{2}$ binding, $\mathrm{O}_{2}$-activation and oxygenation of organic substrates, and electron transfer processes, it seems likely that the heme cofactors can be modulated to favor one type of reactivity over another. There are several ways that heme electronic structure and function can be modulated [23], as summarized in Figure 4 and discussed below.

First, the substituents defining the different types of hemes already change the properties; substituents can be classified as either electron-withdrawing or electron-inducing [147]. A clear example of this was provided by Zhuang et al. whose electron-withdrawing formyl substituents in heme A increase the reduction potential by $179 \mathrm{mV}$ [93]. Correspondingly, a recent study by Shibata et al. documented the effect of electron-withdrawing trifluoromethyl groups on the $\mathrm{O}_{2}$-binding [149].

Due to computational cost considerations, most theoretical studies of heme have been conducted without side chains; however, the heme side chains withdraw substantial electron density from the iron center, to the effect of reducing the isomer shift by $\sim 0.07 \mathrm{~mm} / \mathrm{s}$ and increasing the Weiss character of the $\mathrm{Fe}-\mathrm{O}_{2}$ bond [121]. Correspondingly, the experimental isomer shift of $0.92 \mathrm{~mm} / \mathrm{s}$ for deoxymyoglobin is closely reproduced $(0.93 \mathrm{~mm} / \mathrm{s})$ when side chains are included, but porphyrin without side chains gives $0.99 \mathrm{~mm} / \mathrm{s}$ [146]. Thus, the differences in heme substituents affect the significance of Fe(III) vs. Fe(II) [93], as shown schematically in Figure 4 as "X

Second, the conformation of the heme ring can be non-planar, and several conformations define the structures of heme proteins. These conformations and their respective motions can be categorized [22][150]. Such distortion is involved in the metal incorporation step of metalloporphyrin synthesis, as first emphasized by Sigfridsson and Ryde [151].

Third, modulations of the properties of the axial ligands and their immediate environment can substantially change the properties of heme. Valentine et al. first speculated on such modulation effects 
based on analysis of crystal structures of heme proteins published in the seventies [14], and Dawson discussed several further such relationships [152]. Tezcan, Winkler, and Gray studied the effects of the heme environment that can change reduction potentials by several hundred $\mathrm{mV}$ [153]. Poulos and Goodin debated the role of the axial ligands and hydrogen bonds in modulating the redox potential and catalytic function of heme proteins, notably in terms of stabilizing the ferryl intermediate compound I in heme enzymes [154][155]. Site-directed mutagenesis is of major importance in evaluating the magnitude and direction of modulation effects. In the case of cytochrome c, studies of mutant proteins have enabled a detailed understanding of the relationship between amino acid and redox potential [156][157].

In the case of chlorophyll, a systematic DFT study by Ryde and co-workers showed how different axial ligands were chosen in photosystems to tune the redox potential to prevent back transfer of electrons and to also fine-tune excitation wave lengths by up to $\sim 0.25 \mathrm{eV}$ (e.g. $35 \mathrm{~nm}$ for the B-band) [158]. In substituted porphyrin models the substituents directly affect reactivity [159]. For heme complexes, the effect of ligands on the characteristic Q-band at $\sim 550 \mathrm{~nm}$ and the Soret (B) band at $\sim 400 \mathrm{~nm}$ were investigated in substantial detail by Wang and Brinigar; both bands changed by up to $20 \mathrm{~nm}$ as a function of ligand, corresponding to approximately 0.15 and $0.08 \mathrm{eV}$ for the Soret and Q band, respectively [160].

In addition to these three direct modulations, it has also been proposed that electropositive hydrogens may interact with the $\pi$-system of heme to change its properties [161]. There is also a potential issue of the orientation of the axial histidine's imidazole ring, as this ring can be positioned staggered or eclipsed with respect to the equatorial Fe-N bonds of heme, and the anisotropy of the imidazole may cause a polarization effect in the heme [162].

The most well-known example of protein modulation of heme electronic structure is the communication between the four heme groups of hemoglobin [163][164]. Christian Bohr and co-workers 
first observed the sigmoidal $\mathrm{O}_{2}$ saturation curve of hemoglobin that implies cooperative binding [165]. The allosteric mechanism that produces such cooperativity was formulated mathematically by Monod, Wyman, and Changeux in 1965 [166], and this cooperativity has since been a highly researched topic [163][167][168][169]. Perutz and co-workers emphasized the importance of salt bridges in stabilizing the conformations that favored additional binding of $\mathrm{O}_{2}$ and described these two states as the tense and relaxed states of hemoglobin [91][92]. The reduction in the iron out-of-plane distance that accompanies $\mathrm{O}_{2}$-binding may also effectuate an energy contribution that translates into protein conformational changes [91][92].

Ivanovíc-Burmazovic and co-workers recently used three synthetic models with variable access to the distal coordination site of heme: Accordingly, proteins and artificial scaffolds can be tuned to control ligand binding kinetics so that high-pressure effects, which would normally favor the compact bound state and retard dissociation rates, can be balanced or even reversed [170]. This may be a necessary tuning strategy of heme proteins at high pressure, e.g. in deep-diving mammals: A shift in the equilibrium constant $\mathrm{K}_{\mathrm{O} 2}$ of $\mathrm{O}_{2}$ binding could adversely affect the saturation curves of myoglobin and hemoglobin [171]. A survey of myoglobins of deep-diving cetaceans revealed only small differences in $\mathrm{K}_{\mathrm{O} 2}$, suggesting selection pressure to maintain the delicately tuned hemoglobin-myoglobin transport and storage system, with binding and release dependent on the variable partial pressure of $\mathrm{O}_{2}$ within the body [172]. The vital importance of the quantum-mechanically fine-tuned reversible binding of $\mathrm{O}_{2}$ is confirmed by a theoretical analysis of the grave impact on the aerobic dive limit of seals with mutant myoglobins having reduced $\mathrm{K}_{\mathrm{O} 2}$ values [173].

DFT turned out to be a powerful tool for testing modulation effects, because systematic errors cancel to a high extend in comparisons with and without the "modulation". DFT studies have confirmed the substantial axial substitution effects on porphyrin redox potentials [174][175] and on a range of heme- 
related properties important to its chemical functions [176]. Calculations of a series of models of myoglobin mutants [146] indicate that hydrogen bonds to $\mathrm{O}_{2}$ has the following general and statistically significant effects: i) To increase back-bonding as described above, by favoring the Weiss configuration; ii) to consequently lower the strength, increase the length, and activate the $\mathrm{O}-\mathrm{O}$ bond for potential cleavage; iii) to lower Mössbauer isomer shifts reflecting the increased Fe(III) character of the state; iv) to increase the $\mathrm{O}_{2}$ binding affinity by hydrogen-bond stabilization of the adduct [146]. These effects appear in synthetic models that stabilize the "Weiss" resonance form by explicit hydrogen bonding [177] and are summarized in Figure 4 as "X DISTAL". The main structure-spectroscopy correlations that document this importance of back-bonding are shown in Figure 5, which summarizes the effect of changing the distal amino acid residue of myoglobin models[146]. Berryman et al. also studied the effect of different amino acids on the $\mathrm{O}_{2}$-binding energy of heme and also tested the application of rangeseparated functionals to these systems [178].

The spin states are important in the reactivity of hemes and have been recognized to be close in energy for a long time, as described by Griffith and co-workers [179]. These spin states can also be modulated by tuning of axial ligands, as emphasized by Scheidt and co-workers [180][181][182], and studied theoretically by Jensen and Ryde [183] and De Visser [184]. Normally, the five-coordinate hemes are high-spin whereas the six-coordinate hemes tend to be low-spin [180]; in contrast, the four-coordinate iron(II)porphyrin is remarkably in an intermediate spin ground state [185], and due to the solvent accessibility of iron's d-orbitals, this spin state is particularly sensitive to solvent effects [85]. In synthetic heme model compounds, the spin state can be modulated directly by weak hydrogen-bond interactions [186].

\section{Dual function of heme proteins by evolved differences in protein polarization}


In the discussion of the dual heme functions of $\mathrm{O}_{2}$ activation vs. reversible $\mathrm{O}_{2}$ binding, hydrogen bond modulation plays a predominant role: Valentine and co-workers first studied hydrogen bonding patterns and their effect on heme properties in detail [187]. An important hint came from the observation that globins tend to have hydrogen bonds from backbone carbonyl oxygens to the proximal histidine, whereas some $\mathrm{O}_{2}$-activating enzymes such as heme peroxidases tend to have hydrogen bonds to a carboxylate side chain [183]. DFT calculations identified a significant tendency towards partial deprotonation and increased $\sigma$-donation of the proximal histidine in the models with carboxylate, leading to shorter axial $\mathrm{Fe}-\mathrm{N}$ bonds that selectively stabilize the $\mathrm{Fe}(\mathrm{III})$ and $\mathrm{Fe}(\mathrm{IV})$ states required for the heme enzymes, whereas the hydrogen bond to carbonyl oxygen in the globins does not provide the same contribution to O-O bond cleavage [183] ("X PROXIMAL" in Figure 4).

Perhaps of equal interest, the high- and low-spin states are modulated by the change in ligand field strength of the proximal histidine so that the gap is smallest for the iron(II) systems when the proximal histidine is neutral, but for the Fe(III) state when the proximal histidine is partially deprotonated [183]. Thus, spin crossover and stabilization of relevant oxidation states are both tuned to the desired directions by the axial ligand modulation. It is fascinating how natural evolution has led to the fine-tuning of this polarization by amino acids to produce two markedly different kinds of chemistry, activation (i.e. use) vs. reversible binding (i.e. transport and storage), both essential to a proficient infrastructure of oxygen-based life. 

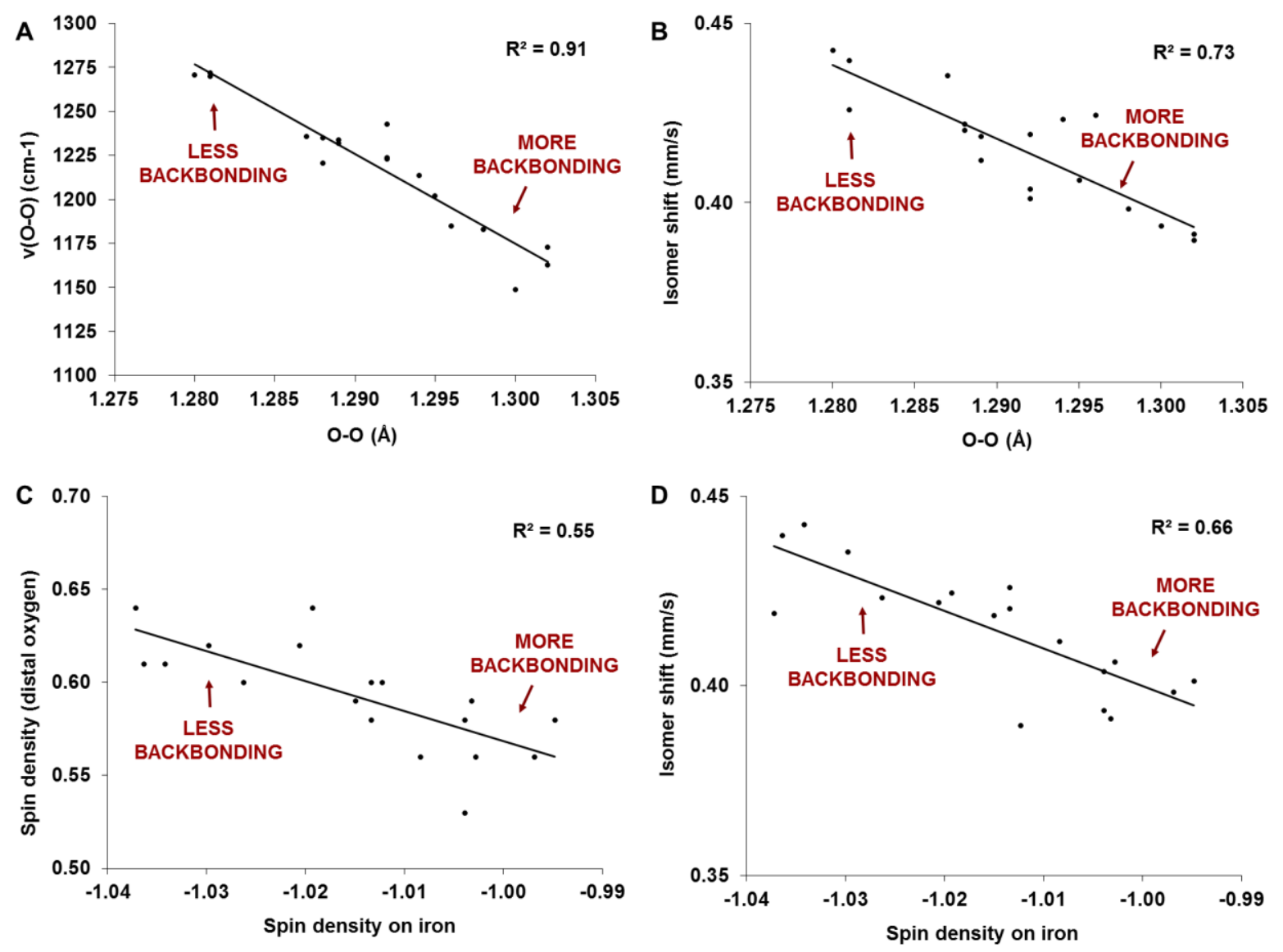

Figure 5. The importance of back-bonding in heme- $\mathrm{O}_{2}$ adducts with variable distal interactions, quantified by structure-spectroscopy correlations deduced from DFT. A) O-O stretch frequency vs. $\mathrm{O}-\mathrm{O}$ bond length; B) Mössbauer isomer shift vs. $\mathrm{O}-\mathrm{O}$ bond length; $\mathrm{C}$ ) spin density on distal oxygen (oxygen farthest from iron) vs. spin density on iron; D) Mössbauer isomer shift vs. spin density on iron. Copyright 2013, American Chemical Society. The figure was modified relative to the original to emphasize the strong and weak back-bonding regimes [146]. 


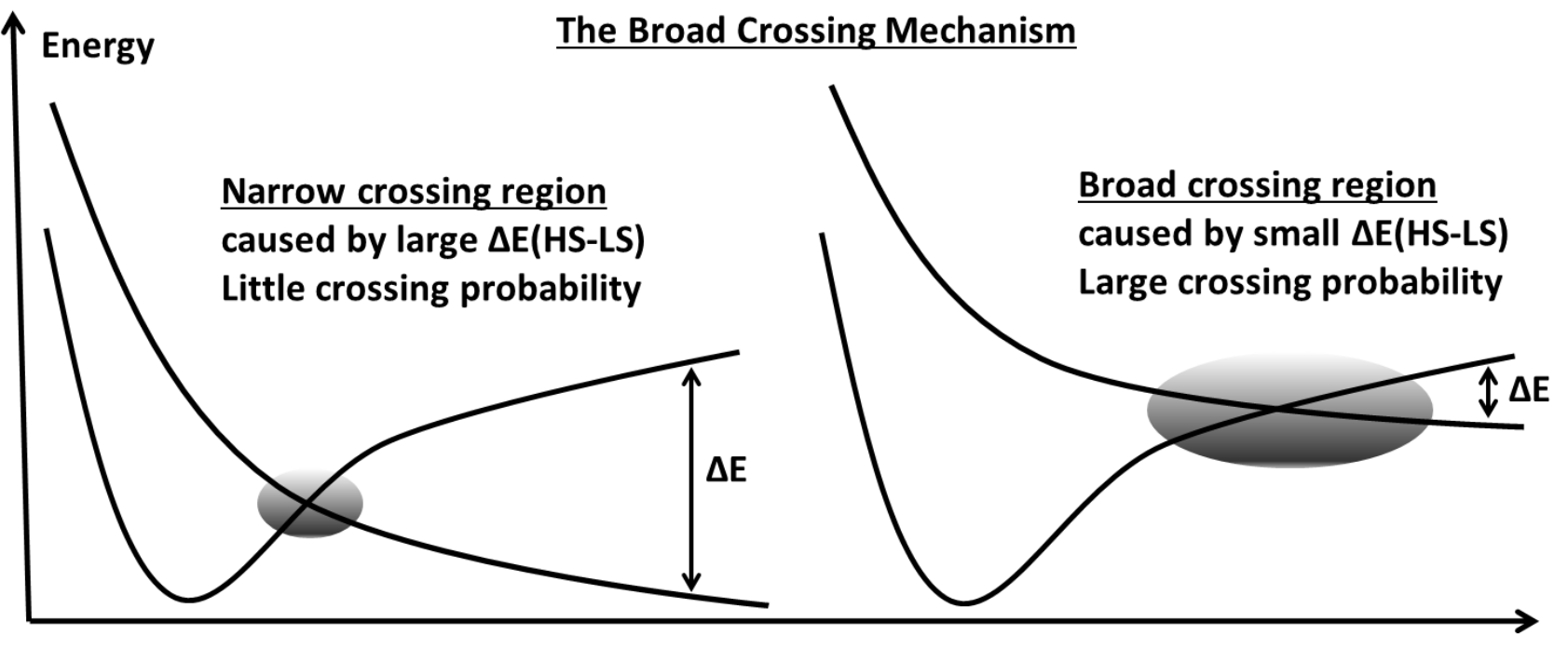

Figure 6. The broad-crossing mechanism of ligand binding to heme: Small ligands can bind to deoxyheme despite the spin-forbidden nature of these processes and the limited $(<5 \mathrm{~kJ} / \mathrm{mol})$ spin-orbit coupling; this is essentially due to the evolved topology of the potential energy surfaces of heme with extremely close-lying spin states over an extended region of the surface that increases crossover probability far beyond that of related systems (the scheme is inspired by a similar scheme in Ref. [121], copyright 2013 John Wiley \& Sons).

As an alternative theory of the dual-function modulation of heme proteins, it has been suggested that specific protein conformations enforce differences in the structure and function of similar tetrapyrrole cofactors, as these distortions may tune the redox potentials and guide the distinct types of reactivity [188]. It is likely that both the choice of axial ligands, the hydrogen bonding to immediate neighbors, the local environment of the heme, and long-range protein effects contribute to the modulation of heme reactivity, as there is no reason why nature should not use all tools at its disposal; the full interplay and relative magnitudes of these effects still remain to be elucidated. 


\section{Ligand binding to heme: Forbidden but feasible}

Having outlined the general principles of the electronic structure of the $\mathrm{O}_{2}$-heme adduct and its modulation by various strategies, the second fundamental question of concern was: How does the heme system facilitate fast and reversible binding of $\mathrm{O}_{2}$, considering the spin-forbidden nature of this process? As stated in the beginning of this review, $\mathrm{O}_{2}$ has a triplet ground state, and the first excited singlet state is inconveniently at $\sim 1 \mathrm{eV}$ above this ground state [23]. The unpaired electron density of the $\pi^{*}$ orbitals are reluctant to react with organic molecules, partly because of the low spin-orbit coupling of the involved atoms and partly because of the high energy of excited singlets of the oxygen species on the corresponding potential energy surfaces (PES) of oxidation reactions, which makes the transition states energetically inaccessible even if the spin-orbit coupling were moderate.

This problem was first studied with DFT methods in the case of CO binding by Harvey who established several principles of the process [189]; a few years later, in 2002, Franzen used a geometrically fixed model iron porphyrin to calculate the PES of $\mathrm{O}_{2}$ dissociation [190]. Although the fixation of the heme geometry leads to errors of up to $100 \mathrm{~kJ} / \mathrm{mol}$, the important novelty of Franzen's work was the application of Landau-Zener formula [191][192] to the estimation of crossover probabilities for a DFT-derived PES of this process. The related photo-dissociation of the $\mathrm{O}_{2}$ - and CO-adducts was studied by time-dependent DFT by De Angelis et al. in 2003 [193].

In 2004, Jensen and Ryde [144] computed the first fully relaxed PES for $\mathrm{O}_{2}$ binding to heme; they also applied the Landau-Zener formula and emphasized tuning of crossing probabilities in two ways to circumvent the fixed (i.e. non-tunable by natural evolution) spin-orbit coupling: either by the energy differences of the involved spin states of the PES, or by the gradient differences of the PES topology. Accordingly, spin-forbidden ligand binding was mainly facilitated by allowing the spin states to be close in energy at dissociation and association. This remarkably produces a "broad crossing region" which 
maximizes crossover probability (Figure 6). In other words, by evolving a deoxyheme with close-lying electronic states of variable spin, including an excited triplet state at $10 \mathrm{~kJ} / \mathrm{mol}$ above the quintet ground state [194], fast reversible crossing was achieved. This mechanism, referred to as the "broad crossing mechanism" [121] remains a useful design principle for spin-forbidden ligand binding to first row transition metals where spin orbit coupling is limited to a few $\mathrm{kJ} / \mathrm{mol}$ [144].

In 2012, Ali et al. studied the structure and PES of $\mathrm{O}_{2}$ binding to heme in detail and reported under-binding of B3LYP [195], consistent with other findings [85][121]. Because of the potential errors due to method choice and neglect of side chains of heme, the full heme with side chains and account for dispersion interactions was subsequently studied [121]. The interactions of the side chains with the ligand contributes to the PES, and dispersion effects are required to model this process accurately, producing first-time agreement with both the experimental barrier of $82 \mathrm{~kJ} / \mathrm{mol}$ and the enthalpy of binding of -59 $\mathrm{kJ} / \mathrm{mol}$ [196] when using the functional TPSSh with D3 dispersion corrections [197] for the full heme system [121]. The broad crossing region is obtained both with B3LYP and TPSSh, although the latter PES is in better agreement with experimental thermochemical data [121].

It is notable that the close-lying spin states of hemes are evident not only in the globins, but also in various states of heme enzymes such as peroxidases and cytochrome $\mathrm{P}_{450}$; the proximity of these spin states has induced the proposal of the "two state reactivity" of heme enzymes by Shaik and co-workers [198]. The initial spin-forbidden binding of ligand to heme has, as argued above, been the subject of substantial evolutionary optimization because this step could otherwise be slow and rate-limiting. However, in other steps of the catalytic cycles of heme enzymes, during binding and dissociation of ligands to iron, the broad crossing regions are probably still required to facilitate fast reactions. The broad crossing mechanism contributes many orders of magnitude to reactivity by facilitating spin inversion [121]. In compound I of some heme enzymes, the doublet and quartet states are particularly close in 
energy due to the antiferromagnetic vs. ferromagnetic coupling of an intermediate spin Fe(IV) with a ligand-based radical [199]. This radical delocalization is a further trick used to facilitate oxygen activation; the spin states of the resting states are already close in energy due to tuning of the ligand field by hydrogen bonds [183]. In this author's opinion, the most important reactivity gain still lies in the facilitation of spin inversion by the broad crossing region caused by close-lying spin states that accelerate binding rates by orders of magnitude [144], and not so much in the actual contribution of two specific states to reactivity (which would roughly double the rate in the simplest case). When $\mathrm{O}_{2}$ binds to deoxyheme, there are already two states reacting, i.e. a triplet and quintet coupled to either a heptet or a triplet [190]. Neither of these states would be very reactive, given the modest spin orbit coupling of heme systems, had it not been for the special evolution of the close-lying quintet and triplet states of deoxyheme that produce a PES with a broad crossing region [144].

In the proteins, Olson and co-workers have systematically worked to increase our understanding of the kinetics and thermodynamics of the ligand binding process, in particular in engineered myoglobin mutants [200][201][202]. These studies have added additional insight into the control of the protein in directing the ligand to and from the distal heme site. The rates of ligand dissociation and recombination measured experimentally in these studies reveal how remarkable effective and reversible these processes are.

\section{Binding of $\mathrm{CO}$ and NO to heme}

Hemes evolved to bind oxygen-based diatomic ligands such as $\mathrm{O}_{2}, \mathrm{NO}$, and $\mathrm{CO}$ with the distinct bond orders $2,2 \frac{1}{2}$, and 3 corresponding to 2,1 , and 0 unpaired electrons in the $\pi^{*}$ orbitals. This difference (as well as the change in proton number by 1 or 2 of the ligand donor atom) influences the way heme binds to these three ligands, and these differences have been the subject of substantial scrutiny [203], in 
particular given the biological roles of all heme-ligand adducts in cellular signaling [204]. Strickland and Harvey have studied by DFT the processes of binding of all three ligands, $\mathrm{CO}, \mathrm{NO}$, and $\mathrm{O}_{2}$ to heme, providing a very useful basis for comparison of the three ligands [205].

The role of the nitric oxide radical as an important signaling molecule in mammals was discovered in the eighties and gained wide-spread appreciation in the nineties [206], with the 1998 Nobel prize in physiology and medicine awarded to Furchgott, Ignarro, and Murad for this discovery. Heme plays a central role in regulating NO, notably by being required for NO synthesis by nitric oxide synthase [207]; NO can bind ferrous and ferric forms of the heme group to regulate its own synthesis by negative feedback [208].

The distinct bonding of NO to heme compared to $\mathrm{CO}$ is due to the additional $\pi^{*}$ electron in NO to heme and its notable back-bonding, as studied in detail by $\mathrm{Xu}$ and Spiro, [209]. As recently summarized by Hunt and Lehnert [210], the electronic structure of the NO adduct is largely responsible for its signaling role: In particular, the strong $\mathrm{Fe}-\mathrm{NO} \sigma$-bond of the ferrous heme adduct in soluble guanylate cyclase weakens the trans proximal $\mathrm{Fe}-\mathrm{N}$ bond and thereby causes a conformational change that triggers synthesis of cyclic guanosine monophosphate, an important second messenger and activator of kinases.

Of similar interest has been the binding of $\mathrm{CO}$ to myoglobin, compared to $\mathrm{O}_{2}$. While $\mathrm{O}_{2}$ binds in a bent geometry, as expected from a consideration of its lone pair Lewis structure and predicted already by Pauling [97], CO is expected to bind linearly due to its sp-hybridized single lone pair on carbon in the weak binding limit. However, if bonding is strong, electronic redistribution would enable a bent geometry of the $\mathrm{CO}$ adduct. $\mathrm{CO}$ binds 10,000-fold more strongly to heme than $\mathrm{O}_{2}$ does, a feature that explains why $\mathrm{CO}$ is toxic to animals in larger amounts, but in the proteins, this selectivity is reduced to $\sim 100$ [203]; 
the nature of the protein's ability to shift the selectivity has been a subject of substantial scrutiny [110][111][211][212].

Initial structures of the $\mathrm{CO}$-adduct of myoglobin indicating a bent structure inspired the idea of Collman et al. that steric strain, i.e. repulsion between electron clouds of CO and near-by distal amino acid residues of the protein pocket, forced $\mathrm{CO}$ into a non-optimal bent geometry to reduce its binding affinity [110]. However, more than twenty structures of synthetic heme CO adducts contain limited bending [211]; Olson and Phillips, based on thermochemical data of site-directed mutants, suggested that the protein-imposed change in selectivity was mainly due to electrostatics [212]. From vibrational spectra and DFT calculations, Spiro and Kozlowski [111] argued against the steric mechanism as the initial crystal structures did not actually support a bent structure due to poor resolution in the FeCO region. Sigfridsson and Ryde confirmed, based on DFT calculations, that the experimental selectivity between $\mathrm{O}_{2}$ and $\mathrm{CO}$ binding could be largely described by normal electrostatic polarization effects [213].

Finally, a new near-atomic resolution crystal structure of the $\mathrm{CO}$ adduct of myoglobin by Kachalova et al. showed that CO binds nearly linearly [214], ending the debate on the binding geometry of $\mathrm{CO}$ once and for all. $\mathrm{CO}$ is a strong $\pi$-acceptor ligand with enhanced back-bonding properties compared to $\mathrm{O}_{2}$; the amount of this back-bonding correlates with the bond strength [111][147]. The simplest way for the protein to effectuate such a change in affinity is via polarization effects [147][200][213][215]. Now, the CO is more polar, but in particular binds more strongly due to its stronger $\pi$-acceptor tendency vs. $\mathrm{O}_{2}$. In the light of the bonding described above, it is conceivable that less favorably positioned hydrogen bonds from the distal histidine lowers the $\mathrm{CO} / \mathrm{O}_{2}$ selectivity as it reduces the $\pi$-acceptor capabilities of $\mathrm{CO}$.

\section{Conclusions}


The purpose of this review has been to show how fundamental quantum mechanics, in the form of the controlled spin-forbidden binding of $\mathrm{O}_{2}$ to heme, plays a dominant role in the evolution and maintenance of life as we know it. Without the porphyrin ring, it is hard to imagine how the photoautotrophic life forms based on $\pi-\pi$ excitations and electron transfer to harvest the photon energy of our near-by yellow G-star could have ever been united with the need for exquisite $\mathrm{O}_{2}$-managing carried out by heme; as it is, we now know that all the three defining features of photosensitizing, electron transfer, and spin crossover are present within the very same porphyrin ring. This is an outstanding achievement of such a simple molecular system, and without it none of this, including this review and its reading, would probably have ever occurred.

The spin crossover nature of the moderate ligand field of heme, evident from its close-lying excited spin states [194], enables fast inversion of spin as required for routine $\mathrm{O}_{2}$ binding as emphasized by the broad crossing mechanism. The back-bonding into the $\mathrm{O}-\mathrm{O}$ bond, tuned by multiple strategies of the heme protein, determines the nature of $\mathrm{O}_{2}$ management: A moderate back-bonding to $\mathrm{O}_{2}$ produces relatively weak and reversible binding, as fit for transport and occasional storage; this type of bonding is achieved in the ingenious $\mathrm{O}_{2}$ transport-storage system constituted by myoglobin and hemoglobin. In contrast, strong back-bonding is facilitated by hydrogen-bonding to the $\mathrm{O}_{2}$ or by electrostatic polarization of the proximal ligand to favor the high-valent resonance forms of iron. Without heme and its intriguing dual abilities of $\mathrm{O}_{2}$-transport and activation, $\mathrm{O}_{2}$ could probably not have been used to the extent that we know today.

There was rarely an example clearer than this of the direct reliance of life as we know it on the almost miraculous quantum mechanical properties of a single molecular system. The binding of $\mathrm{O}_{2}$ to heme is a truly quantum mechanical phenomenon with vast consequences for life, not just in terms of immediate suffocation if this spin crossover disappeared but also, in a larger context, in the ability to use 
$\mathrm{O}_{2}$ as the main electron acceptor of the energy-rich electrons of organic matter that define heterotrophic life on this planet.

\section{References}

[1] R.J. Boyd, Nature 310 (1984) 480.

[2] J. Katriel, R. Pauncz, in:, P.-O. Löwdin (Ed.), Adv. Quantum Chem., Academic Press, 1977, pp. $143-185$.

[3] E.G. Nisbet, N.H. Sleep, Nature 409 (2001) 1083.

[4] R.E. Blankenship, Photosynth. Res. 33 (1992) 91.

[5] P.G. Falkowski, L. V Godfrey, Philos. Trans. R. Soc. B Biol. Sci. 363 (2008) 2705.

[6] A. Tomitani, A.H. Knoll, C.M. Cavanaugh, T. Ohno, Proc. Natl. Acad. Sci. U. S. A. 103 (2006) 5442.

[7] J. Raymond, D. Segrè, Science (80-. ). 311 (2006) 1764.

[8] D.K. Dowling, L.W. Simmons, Proc. R. Soc. London B Biol. Sci. (2009).

[9] G.L. Semenza, Science (80-. ). 318 (2007) 62.

[10] N.S. Chandel, G.R.S. Budinger, Free Radic. Biol. Med. 42 (2007) 165.

[11] I. Hamza, H.A. Dailey, Biochim. Biophys. Acta - Mol. Cell Res. 1823 (2012) 1617.

[12] S. Granick, in:, Evol. Genes Proteins, 1965, pp. 67-68.

[13] T.L. Poulos, Arch. Biochem. Biophys. 500 (2010) 3. 
[14] J.S. Valentine, R.P. Sheridan, L.C. Allen, P.C. Kahn, Proc. Natl. Acad. Sci. 76 (1979) 1009.

[15] T. Yonetani, K. Kanaori, Biochim. Biophys. Acta 1834 (2013) 1873.

[16] H. Mairbäurl, R.E. Weber, Compr. Physiol. (2012).

[17] J.G. Kleingardner, K.L. Bren, Acc. Chem. Res. 48 (2015) 1845.

[18] J. Blumberger, Chem. Rev. 115 (2015) 11191.

[19] B.G. Malmstroem, Chem. Rev. 90 (1990) 1247.

[20] S. Yoshikawa, A. Shimada, Chem. Rev 115 (2015) 1936.

[21] J.P. Collman, R. Boulatov, C.J. Sunderland, L. Fu, Chem. Rev. 104 (2004) 561.

[22] J. A. Shelnutt, X.-Z. Song, J.-G. Ma, S.-L. Jia, W. Jentzen, C. J. Medforth, C. J. Medforth, Chem. Soc. Rev. 27 (1998) 31.

[23] M. Momenteau, C.A. Reed, Chem. Rev. 94 (1994) 659.

[24] S. Hematian, I. Garcia-Bosch, K.D. Karlin, Acc. Chem. Res. 48 (2015) 2462.

[25] M. Sono, M.P. Roach, E.D. Coulter, J.H. Dawson, Chem. Rev. 96 (1996) 2841.

[26] A. Wilks, G. Heinzl, Arch. Biochem. Biophys. 544 (2014) 87.

[27] P.R. Ortiz de Montellano, Annu. Rev. Pharmacol. Toxicol. 32 (1992) 89.

[28] B. Meunier, S.P. de Visser, S. Shaik, Chem. Rev. 104 (2004) 3947.

[29] T.L. Poulos, Chem. Rev. 114 (2014) 3919.

[30] L. Olsen, C. Oostenbrink, F.S. Jorgensen, Adv. Drug Deliv. Rev. 86 (2015) 61. 
[31] I.G. Denisov, T.M. Makris, S.G. Sligar, I. Schlichting, Chem. Rev. 105 (2005) 2253.

[32] A. Wilks, Antioxid. Redox Signal. 4 (2002) 603.

[33] A.T. Smith, S. Pazicni, K.A. Marvin, D.J. Stevens, K.M. Paulsen, J.N. Burstyn, Chem. Rev. 115 (2015) 2532.

[34] I. Hamza, ACS Chem. Biol. 1 (2006) 627.

[35] M.D. Maines, A. Kappas, Science (80-. ). 198 (1977) 1215.

[36] A. Lazcano, Hematology 17 (2012) s7.

[37] K. Shikama, A. Matsuoka, Structure-Function Relationships in Unusual Nonvertebrate Globins, 2004.

[38] J.F. Storz, Physiology 31 (2016) 223.

[39] F. Hoyle, Mon. Not. R. Astron. Soc. 106 (1946) 343.

[40] E.M. Burbidge, G.R. Burbidge, W.A. Fowler, F. Hoyle, Rev. Mod. Phys. 29 (1957) 547.

[41] J.W. Morgan, E. Anders, Proc. Natl. Acad. Sci. U. S. A. 77 (1980) 6973.

[42] R.G. Pearson, J. Am. Chem. Soc. 85 (1963) 3533.

[43] J. Meyer, J. Biol. Inorg. Chem. 13 (2008) 157.

[44] H. Beinert, R.H. Holm, E. Münck, Science (80-. ). 277 (1997) 653.

[45] J.L. Crossland, D.R. Tyler, Coord. Chem. Rev. 254 (2010) 1883.

[46] W.M. Reiff, G.J. Long, Mössbauer Spectrosc. Appl. to Inorg. Chem. 1 (2013) 245. 
[47] P.R.O. De Montellano, Cytochrome P450: Structure, Mechanism, and Biochemistry, Springer Science \& Business Media, 2005.

[48] P. Gütlich, H.A. Goodwin, in:, Spin Crossover Transit. Met. Compd. I, Springer, 2004, pp. 147.

[49] F. Widdel, S. Schnell, S. Heising, A. Ehrenreich, B. Assmus, B. Schink, Nature 362 (1993) 834.

[50] K.P. Jensen, J. Inorg. Biochem. 100 (2006) 1436.

[51] K.P. Jensen, J. Inorg. Biochem. 102 (2008) 87.

[52] K.P. Jensen, U. Ryde, Coord. Chem. Rev. 253 (2009) 769.

[53] R.C. Hardison, Proc. Natl. Acad. Sci. U. S. A. 93 (1996) 5675.

[54] T.A.K. Freitas, S. Hou, E.M. Dioum, J.A. Saito, J. Newhouse, G. Gonzalez, M.-A. GillesGonzalez, M. Alam, Proc. Natl. Acad. Sci. U. S. A. 101 (2004) 6675.

[55] S. Hou, T. Freitas, R.W. Larsen, M. Piatibratov, V. Sivozhelezov, A. Yamamoto, E.A. Meleshkevitch, M. Zimmer, G.W. Ordal, M. Alam, Proc. Natl. Acad. Sci. U. S. A. 98 (2001) 9353.

[56] D. Shemin, C.S. Russell, J. Am. Chem. Soc. 75 (1953) 4873.

[57] N.S. Radin, D. Rittenberg, D. Shemin, J. Biol. Chem. 184 (1950) 745.

[58] S. Granick, Ann. N. Y. Acad. Sci. 69 (1957) 292.

[59] J. Xiong, W.M. Fischer, K. Inoue, M. Nakahara, C.E. Bauer, Science (80-. ). 289 (2000) 1724.

[60] J.S. Lindsey, V. Chandrashaker, M. Taniguchi, M. Ptaszek, New J. Chem. 35 (2011) 65. 
[61] G. Schwarzenbach, Helv. Chim. Acta 35 (1952) 2344.

[62] H.J.H. Fenton, J. Chem. Soc. Trans. 65 (1894) 899.

[63] R.A. Marcus, J. Chem. Phys. 24 (1956).

[64] R.A. Marcus, N. Sutin, Biochim. Biophys. Acta (BBA)-Reviews Bioenerg. 811 (1985) 265.

[65] N.S. Hush, Trans. Faraday Soc. 57 (1961) 557.

[66] K.P. Jensen, U. Ryde, ChemBioChem 4 (2003) 413.

[67] E. Sigfridsson, M.H.M. Olsson, U. Ryde, J. Phys. Chem. B 105 (2001) 5546.

[68] E. Hückel, Zeitschrift Für Phys. 70 (1931) 204.

[69] J.L. Soret, Compt Rend 97 (1883) 1269.

[70] M. Gouterman, J. Chem. Phys. 30 (1959) 1139.

[71] M. Gouterman, J. Mol. Spectrosc. 6 (1961) 138.

[72] W.M. Campbell, K.W. Jolley, P. Wagner, K. Wagner, P.J. Walsh, K.C. Gordon, L. SchmidtMende, M.K. Nazeeruddin, Q. Wang, M. Grätzel, J. Phys. Chem. C 111 (2007) 11760.

[73] A. Yella, H.-W. Lee, H.N. Tsao, C. Yi, A.K. Chandiran, M.K. Nazeeruddin, E.W.-G. Diau, C.Y. Yeh, S.M. Zakeeruddin, M. Grätzel, Science (80-. ). 334 (2011) 629.

[74] L.-L. Li, E.W.-G. Diau, Chem. Soc. Rev. 42 (2013) 291.

[75] C.I. Simionescu, R. Mora, B.C. Simionescu, Bioelectrochemistry Bioenerg. 5 (1978) 1.

[76] R. Tsuchida, Bull. Chem. Soc. Jpn. 13 (1938) 388. 
[77] Y. Shimura, R. Tsuchida, Bull. Chem. Soc. Jpn. 29 (1956) 311.

[78] J. Josephsen, C.E. Schaffer, Acta Chem. Scandin. A 31 (1977) 813.

[79] S.R. Mortensen, K.P. Kepp, J. Phys. Chem. A 119 (2015) 4041.

[80] K.P. Kepp, J. Inorg. Biochem. 105 (2011) 1286.

[81] T. Ikeue, Y. Ohgo, T. Yamaguchi, M. Takahashi, M. Takeda, M. Nakamura, Angew. Chemie Int. Ed. 40 (2001) 2617.

[82] K.P. Kepp, Inorg. Chem. 55 (2016) 2717.

[83] C. Rovira, K. Kunc, J. Hutter, M. Parrinello, Inorg. Chem. 40 (2001) 11.

[84] K.P. Jensen, U. Ryde, J. Porphyr. Phthalocyanines 9 (2005) 581.

[85] K.P. Kepp, Coord. Chem. Rev. 257 (2013) 196.

[86] I.U. Heinemann, M. Jahn, D. Jahn, Arch. Biochem. Biophys. 474 (2008) 238.

[87] K.P. Jensen, P. Rydberg, J. Heimdal, U. Ryde, Comput. Model. Homog. Enzym. Catal. A Knowledge-Base Des. Effic. Catal. (2008) 27.

[88] R.J. Boyd, Nature 250 (1974) 566.

[89] J.M. Ugalde, B. Dunietz, A. Dreuw, M. Head-Gordon, R.J. Boyd, J. Phys. Chem. A 108 (2004) 4653.

[90] V.E.J. Walker, N. Castillo, C.F. Matta, R.J. Boyd, J. Phys. Chem. A 114 (2010) 10315.

[91] M.F. Perutz, Proc. R. Soc. London. Ser. B, Biol. Sci. 208 (1980) 135.

[92] M.F. Perutz, Annu. Rev. Biochem. 48 (1979) 327. 
[93] J. Zhuang, A.R. Reddi, Z. Wang, B. Khodaverdian, E.L. Hegg, B.R. Gibney, Biochemistry 45 (2006) 12530.

[94] T. Mogi, K. Saiki, Y. Anraku, Mol. Microbiol. 14 (1994) 391.

[95] M. Kotani, Ann. N. Y. Acad. Sci. 158 (1969) 20.

[96] R.K. Hocking, E.C. Wasinger, Y.-L. Yan, F.M.F. deGroot, F. Ann Walker, K.O. Hodgson, B. Hedman, E.I. Solomon, J. Am. Chem. Soc. 129 (2007) 113.

[97] L. Pauling, C.D. Coryell, Proc. Natl. Acad. Sci. U. S. A. 22 (1936) 210.

[98] K.L. Bren, R. Eisenberg, H.B. Gray, Proc. Natl. Acad. Sci. 112 (2015) 13123.

[99] D.S. McClure, Radiat. Res. Suppl. 2 (1960) 218.

[100] J.J. Weiss, Nature 202 (1964) 83.

[101] L. Ferrand, S. Soorkia, G. Grégoire, M. Broquier, B. Soep, N. Shafizadeh, Phys. Chem. Chem. Phys. 17 (2015) 25693.

[102] L. Pauling, Nature 203 (1964) 182.

[103] W.A. 3rd Goddard, B.D. Olafson, Proc. Natl. Acad. Sci. U. S. A. 72 (1975) 2335.

[104] L. Pauling, Proc. Natl. Acad. Sci. U. S. A. 74 (1977) 2612.

[105] B.H. Huynh, D.A. Case, M. Karplus, J. Am. Chem. Soc. 99 (1977) 6103.

[106] R.D. Harcourt, Chem. Phys. Lett. 167 (1990) 374.

[107] S. Yamamoto, H. Kashiwagi, Chem. Phys. Lett. 161 (1989) 85.

[108] R.D. Harcourt, J. Biol. Inorg. Chem. 19 (2013) 113. 
[109] R.D. Harcourt, in:, Bond. Electron-Rich Mol., Springer, 2016, pp. 231-246.

[110] J.P. Collman, J.I. Brauman, T.R. Halbert, K.S. Suslick, Proc. Natl. Acad. Sci. 73 (1976) 3333.

[111] T.G. Spiro, P.M. Kozlowski, Acc. Chem. Res. 34 (2001) 137.

[112] B.A. Wittenberg, L. Kampa, J.B. Wittenberg, W.E. Blumberg, J. Peisach, J. Biol. Chem. 243 (1968) 1863.

[113] J. Peisach, W.E. Blumberg, B.A. Wittenberg, J.B. Wittenberg, J. Biol. Chem. 243 (1968) 1871.

[114] L. Vickery, T. Nozawa, K. Sauer, J. Am. Chem. Soc. 98 (1976) 343.

[115] M.I. Oshtrakh, A.L. Berkovsky, A. Kumar, S. Kundu, A. V Vinogradov, T.S. Konstantinova, V.A. Semionkin, Biometals 24 (2011) 501.

[116] F.A. Walker, Coord. Chem. Rev. 185-186 (1999) 471.

[117] K. Atak, R. Golnak, J. Xiao, E. Suljoti, M. Pflüger, T. Brandenburg, B. Winter, E.F. Aziz, J. Phys. Chem. B 118 (2014) 9938.

[118] T. Kent, K. Spartalian, G. Lang, T. Yonetani, Biochim. Biophys. Acta (BBA)-Protein Struct. 490 (1977) 331.

[119] T.A. Kent, K. Spartalian, G. Lang, T. Yonetani, C.A. Reed, J.P. Collman, Biochim. Biophys. Acta (BBA)-Protein Struct. 580 (1979) 245.

[120] M.I. Oshtrakh, A. Kumar, S. Kundu, A.L. Berkovsky, V.A. Semionkin, J. Mol. Struct. 993 (2011) 292.

[121] K.P. Kepp, ChemPhysChem 14 (2013) 3551. 
[122] M.A. Sowole, S. Vuong, L. Konermann, Anal. Chem. 87 (2015) 9538.

[123] A. Ghosh, J. Almlöf, Chem. Phys. Lett. 213 (1993) 519.

[124] A. Ghosh, Acc. Chem. Res. 31 (1998) 189.

[125] D.H. Jones, A.S. Hinman, T. Ziegler, Inorg. Chem. 32 (1993) 2092.

[126] P.M. Kozlowski, M.Z. Zgierski, P. Pulay, Chem. Phys. Lett. 247 (1995) 379.

[127] J. Finley, P.-Å. Malmqvist, B.O. Roos, L. Serrano-Andrés, Chem. Phys. Lett. 288 (1998) 299.

[128] M. Merchán, E. Ortí, B.O. Roos, Chem. Phys. Lett. 226 (1994) 27.

[129] M.T. McMahon, A.C. deDios, N. Godbout, R. Salzmann, D.D. Laws, H. Le, R.H. Havlin, E. Oldfield, J. Am. Chem. Soc. 120 (1998) 4784.

[130] Y. Zhang, J. Mao, E. Oldfield, J. Am. Chem. Soc. 124 (2002) 7829.

[131] J. Vojtechovský, K. Chu, J. Berendzen, R.M. Sweet, I. Schlichting, Biophys. J. 77 (1999) 2153.

[132] W.A. Eaton, L.K. Hanson, P.J. Stephens, J.C. Sutherland, J.B.R. Dunn, J. Am. Chem. Soc. 100 (1978) 4991.

[133] H. Nakatsuji, J. Hasegawa, H. Ueda, M. Hada, Chem. Phys. Lett. 250 (1996) 379.

[134] G. Ghigo, B.O. Roos, P.-Å. Malmqvist, Chem. Phys. Lett. 396 (2004) 142.

[135] K.P. Jensen, B. Roos, U. Ryde, J. Inorg. Biochem. 99 (2005) 45.

[136] K.P. Jensen, B.O. Roos, U. Ryde, J. Inorg. Biochem. 99 (2005) 978.

[137] M. Radon, K. Pierloot, J. Phys. Chem. A 112 (2008) 11824. 
[138] S. Vancoillie, H. Zhao, M. Radon, K. Pierloot, J. Chem. Theory Comput. 6 (2010) 576.

[139] M. Radon, E. Broclawik, K. Pierloot, J. Phys. Chem. B 114 (2010) 1518.

[140] H. Chen, M. Ikeda-Saito, S. Shaik, J. Am. Chem. Soc. 130 (2008) 14778.

[141] S. Shaik, H. Chen, J. Biol. Inorg. Chem. 16 (2011) 841.

[142] A. Ghosh, P.R. Taylor, J. Chem. Theory Comput. 1 (2005) 597.

[143] A. Ghosh, J. Biol. Inorg. Chem. 11 (2006) 712.

[144] K.P. Jensen, U. Ryde, J. Biol. Chem. 279 (2004) 14561.

[145] V.E.J. Berryman, R.J. Boyd, E.R. Johnson, J. Chem. Theory Comput. 11 (2015) 3022.

[146] K.P. Kepp, P. Dasmeh, J. Phys. Chem. B 117 (2013) 3755.

[147] T.G. Spiro, A. V Soldatova, G. Balakrishnan, Coord. Chem. Rev. 257 (2013) 511—527.

[148] S.A. Wilson, T. Kroll, R.A. Decreau, R.K. Hocking, M. Lundberg, B. Hedman, K.O. Hodgson, E.I. Solomon, J. Am. Chem. Soc. 135 (2013) 1124.

[149] T. Shibata, E. Furuichi, K. Imai, A. Suzuki, Y. Yamamoto, J. Porphyr. Phthalocyanines 19 (2015) 301.

[150] M.W. Renner, K.M. Barkigia, D. Melamed, J.-P. Gisselbrecht, N.Y. Nelson, K.M. Smith, J. Fajer, Res. Chem. Intermed. 28 (n.d.) 741.

[151] E. Sigfridsson, U. Ryde, J. Biol. Inorg. Chem. 8 (2003) 273.

[152] J.H. Dawson, Science (80-. ). 240 (1988) 433.

[153] F.A. Tezcan, J.R. Winkler, H.B. Gray, J. Am. Chem. Soc. 120 (1998) 13383. 
[154] T.L. Poulos, J. Biol. Inorg. Chem. 1 (1996) 356.

[155] B.D. Goodin, J. Biol. Inorg. Chem. 1 (1996) 360.

[156] G.A. Mauk, R.G. Moore, J. Biol. Inorg. Chem. 2 (1997) 119.

[157] R.M. Gunner, E. Alexov, E. Torres, S. Lipovaca, J. Biol. Inorg. Chem. 2 (1997) 126.

[158] J. Heimdal, K.P. Jensen, A. Devarajan, U. Ryde, J. Biol. Inorg. Chem. 12 (2006) 49.

[159] K.M. Kadish, E. Van Caemelbecke, E. Gueletii, S. Fukuzumi, K. Miyamoto, T. Suenobu, A. Tabard, R. Guilard, Inorg. Chem. 37 (1998) 1759.

[160] C.-M. Wang, W.S. Brinigar, Biochemistry 18 (1979) 4960.

[161] V.B. Medaković, G.A. Bogdanović, M.K. Milčić, G. V Janjić, S.D. Zarić, J. Inorg. Biochem. 117 (2012) 157.

[162] Q. Peng, M. Li, C. Hu, J.W. Pavlik, A.G. Oliver, E.E. Alp, M.Y. Hu, J. Zhao, J.T. Sage, W.R. Scheidt, Inorg. Chem. 52 (2013) 11361.

[163] M.F. Perutz, A.J. Wilkinson, M. Paoli, G.G. Dodson, Annu. Rev. Biophys. Biomol. Struct. 27 (1998) 1 .

[164] W.A. Eaton, E.R. Henry, J. Hofrichter, A. Mozzarelli, Nat Struct Mol Biol 6 (1999) 351.

[165] C. Bohr, K. Hasselbalch, A. Krogh, Skand. Arch. Physiol. 16 (1904) 402.

[166] J. Monod, J. Wyman, J.-P. Changeux, J. Mol. Biol. 12 (1965) 88.

[167] Y. Yuan, M.F. Tam, V. Simplaceanu, C. Ho, Chem. Rev. 115 (2015) 1702.

[168] M. Brunori, Biophys. J. 109 (2015) 1077. 
[169] E.R. Henry, S. Bettati, J. Hofrichter, W.A. Eaton, Biophys. Chem. 98 (2002) 149.

[170] O. Troeppner, R. Lippert, T.E. Shubina, A. Zahl, N. Jux, I. Ivanović-Burmazović, Angew. Chemie 126 (2014) 11636.

[171] P. Dasmeh, K.P. Kepp, Comp. Biochem. Physiol. Part A Mol. Integr. Physiol. 161 (2012) 9.

[172] P. Dasmeh, A.W.R. Serohijos, K.P. Kepp, E.I. Shakhnovich, PLoS Comput. Biol. 9 (2013) e1002929.

[173] P. Dasmeh, R.W. Davis, K.P. Kepp, Comp. Biochem. Physiol. Part A Mol. Integr. Physiol. 164 (2013) 119.

[174] M.-S. Liao, S. Scheiner, J. Comput. Chem. 23 (2002) 1391.

[175] M.-S. Liao, S. Scheiner, J. Chem. Phys. 117 (2002).

[176] P. Rydberg, E. Sigfridsson, U. Ryde, J. Biol. Inorg. Chem. 9 (2004) 203.

[177] K. Mittra, S. Chatterjee, S. Samanta, K. Sengupta, H. Bhattacharjee, A. Dey, Chem. Commun. 48 (2012) 10535.

[178] V.E.J. Berryman, M.G. Baker, R.J. Boyd, J. Phys. Chem. A 118 (2014) 4565.

[179] P. George, J. Beetlestone, J.S. Griffith, Rev. Mod. Phys. 36 (1964) 441.

[180] W.R. Scheidt, C.A. Reed, Chem. Rev. 81 (1981) 543.

[181] D.K. Geiger, Y.J. Lee, W.R. Scheidt, J. Am. Chem. Soc. 106 (1984) 6339.

[182] D.K. Geiger, W.R. Scheidt, Inorg. Chem. 23 (1984) 1970.

[183] K.P. Jensen, U. Ryde, Mol. Phys. 101 (2003) 2003. 
[184] S.P. de Visser, J. Phys. Chem. A 109 (2005) 11050.

[185] T. Kitagawa, J. Teraoka, Chem. Phys. Lett. 63 (1979) 443.

[186] D. Sahoo, M.G. Quesne, S.P. de Visser, S.P. Rath, Angew. Chemie Int. Ed. 54 (2015) 4796.

[187] R. Quinn, J. Mercer-Smith, J.N. Burstyn, J.S. Valentine, J. Am. Chem. Soc. 106 (1984) 4136.

[188] M.O. Senge, S.A. MacGowan, J.M. O’Brien, Chem. Commun. 51 (2015) 17031.

[189] J.N. Harvey, J. Am. Chem. Soc. 122 (2000) 12401.

[190] S. Franzen, Proc. Natl. Acad. Sci. U. S. A. 99 (2002) 16754.

[191] L.D. Landau, Phys. Z. Sowjetunion 2 (1932) 46.

[192] C. Zener, Proc. R. Soc. London A Math. Phys. Eng. Sci. 137 (1932) 696.

[193] F. De Angelis, R. Car, T.G. Spiro, J. Am. Chem. Soc. 125 (2003) 15710.

[194] B.H. Huynh, G.C. Papaefthymiou, C.S. Yen, J.L. Groves, C.S. Wu, J. Chem. Phys. 61 (1974) 3750.

[195] M.E. Ali, B. Sanyal, P.M. Oppeneer, J. Phys. Chem. B 116 (2012) 5849.

[196] T.G. Traylor, A.P. Berzinis, Proc. Natl. Acad. Sci. 77 (1980) 3171.

[197] S. Grimme, J. Antony, S. Ehrlich, H. Krieg, J. Chem. Phys. 132 (2010).

[198] E. Derat, S. Shaik, J. Am. Chem. Soc. 128 (2006) 8185.

[199] D.L. Harris, J.-Y. Park, L. Gruenke, L. Waskell, Proteins 55 (2004) 895.

[200] F. Draghi, A.E. Miele, C. Travaglini-Allocatelli, B. Vallone, M. Brunori, Q.H. Gibson, J.S. 
Olson, J. Biol. Chem. 277 (2002) 7509.

[201] J.S. Olson, G.N. Phillips, J. Biol. Chem. 271 (1996) 17593.

[202] E.E. Scott, Q.H. Gibson, J.S. Olson, J. Biol. Chem. 276 (2001) 5177.

[203] B.A. Springer, S.G. Sligar, J.S. Olson, G.N.J. Phillips, Chem. Rev. 94 (1994) 699.

[204] T. Shimizu, D. Huang, F. Yan, M. Stranava, M. Bartosova, V. Fojtíková, M. Martínková, Chem. Rev. 115 (2015) 6491.

[205] N. Strickland, J.N. Harvey, J. Phys. Chem. B 111 (2007) 841.

[206] E. Culotta, D.E. Koshland, Science (80-. ). 258 (1992) 1862.

[207] R.G. Knowles, S. Moncada, Biochem. J. 298 (1994) 249.

[208] J. Wang, D.L. Rousseau, H.M. Abu-Soud, D.J. Stuehr, Proc. Natl. Acad. Sci. 91 (1994) 10512.

[209] C. Xu, T.G. Spiro, J. Biol. Inorg. Chem. 13 (2008) 613.

[210] A.P. Hunt, N. Lehnert, Acc. Chem. Res. 48 (2015) 2117.

[211] C. Slebodnick, A.J. Ibers, J. Biol. Inorg. Chem. 2 (1997) 521.

[212] S.J. Olson, N.G. Phillips Jr., J. Biol. Inorg. Chem. Chem. 2 (1997) 544.

[213] E. Sigfridsson, U. Ryde, J. Biol. Inorg. Chem. 4 (1999) 99.

[214] G.S. Kachalova, a N. Popov, H.D. Bartunik, Sci. (New York, NY) 284 (1999) 473.

[215] I. Birukou, R.L. Schweers, J.S. Olson, J. Biol. Chem. 285 (2010) 8840. 